CFR working paper No. 11-13

Irrationality or efficiency of macroeconomic survey forecasts? Implications from the anchoring bias rest

D. Hess - s. orbe

centre for financial Research Look deeper 


\title{
Irrationality or Efficiency of Macroeconomic Survey Forecasts? Implications from the Anchoring Bias Test ${ }^{1}$
}

\author{
Dieter Hess \\ University of Cologne \\ Corporate Finance Seminar \\ Albertus-Magnus Platz \\ 50923 Cologne \\ Germany \\ tel: +49 2214707877 \\ email: hess@wiso.uni-koeln.de
}

\author{
Sebastian Orbe \\ University of Cologne \\ Corporate Finance Seminar \\ Albertus-Magnus Platz \\ 50923 Cologne \\ Germany \\ tel: +492214707882 \\ email: orbe@wiso.uni-koeln.de
}

August 2011

\footnotetext{
${ }^{1}$ For valuable comments we are grateful to the participants of the Financial Management Association European Conference 2011 and the Eastern Finance Association Annual Meeting 2011.
} 


\title{
Irrationality or Efficiency of Macroeconomic Survey Forecasts? Implications from the Anchoring Bias Test
}

\begin{abstract}
We analyze the quality of macroeconomic survey forecasts. Recent findings indicate that they are anchoring biased. This irrationality would challenge the results of a wide range of empirical studies, e.g., in asset pricing, volatility clustering or market liquidity, which rely on survey data to capture market participants' expectations. We contribute to the existing literature in two ways. First, we show that the cognitive bias is a statistical artifact. Despite highly significant anchoring coefficients a bias adjustment does not improve forecasts' quality. To explain this counterintuitive result we take a closer look at macroeconomic analysts' information processing abilities. We find that analysts benefit from the use of an extensive information set, neglected in the anchoring bias test. Exactly this information advantage drives the misleading anchoring bias test results. Second, we find that the superior information aggregation capabilities enable analysts to easily outperform sophisticated timeseries forecasts and therefore survey forecasts should clearly be favored.
\end{abstract}

Keywords: macroeconomic announcements, efficiency of forecasts, anchoring bias, rationality of analysts

JEL classification: $\quad$ G12, G14, G17, E17, E37 
A large and growing body of financial market research relies on survey forecasts to isolate the unanticipated information component in scheduled macroeconomic releases. ${ }^{1}$ Recently, Campbell and Sharpe (2009) suggest that there is a substantial "anchoring bias" in analysts' forecasts. This implies that analysts' forecasts would not adequately approximate market participants' expectations since they could be substantially improved. However, we cannot find that macroeconomic analysts' forecasts can be improved - once we apply a look-ahead bias free test and adjustment procedure. In contrast, while anchoring would suggest that analysts' forecasts underperform mechanical time-series models, we find the opposite: macroeconomic analysts substantially outperform mechanical forecasts. This outperformance can be attributed to the fact that analysts use a much richer information set, i.e. they incorporate other information besides the historical time-series the anchoring test focuses on. While analysts' forecasts deviate from time-series forecast, we find that by deviating analysts reduce - not increase - forecasts errors. Moreover, we show that these deviations can be explained largely by other macroeconomic data. More generally, our analysis points out a universal risk inherent in (behavioral) tests focusing on a single time-series property: rational agents' forecasts may deviates from time-series forecasts not only because of cognitive inefficiencies but also because of using a richer information set.

Compared to the extensive research that has been conducted in the area of macroeconomic information processing in financial markets (e.g. Urich and Wachtel (1984), McQueen and Roley (1993), Balduzzi et al. (2001) and Andersen et al.(2003)) comparatively little analysis is available concerning the properties of macroeconomic survey forecasts. This is somewhat surprising, but possibly due to the high quality of survey forecasts. The few thus far available

\footnotetext{
${ }^{1}$ For example, studies on market efficiency, information processing, liquidity around announcements, or volatility clustering use macroeconomic survey forecasts. Most frequently, Money Market Services (MMS) survey data are used, for example, by Urich and Wachtel (1984), McQueen and Roley (1993), Almeida et al. (1998), Elton (1999), Balduzzi et al. (2001), Flannery and Protopapadakis (2002), Andersen et al. (2003), Green (2004), Bernanke and Kuttner (2005), Hautsch and Hess (2007), Evans and Lyons (2008), and Hautsch et al. (2010), to cite only a few.
} 
forecast rationality studies largely test for general quality properties derived from Muth's Rational Expectations Hypothesis $(1961)^{2}$. As a common outcome, general forecast rationality studies provide no evidence of systematic and persistent inefficiencies. ${ }^{3}$ In contrast, Campbell and Sharpe (2009) test for a specific behavioral inefficiency, the anchoring bias, first documented by Tversky and Kahneman (1974) in psychological experiments. Anchoring implies that too much weight is attached to a certain prior available piece of information. In the context of macroeconomic forecasts it would mean that the surveyed analyst puts too much importance on the last months' actual and therefore underweights other important information. Thus the entire information set available at the survey date would not be efficiently incorporated in the forecast generation process. But then, utilizing the entire available information correctly must yield improved forecasts. Only if this is the case, the widely used survey forecasts would have to be viewed as inefficient and poor proxies of market participant's expectations.

However, we cannot reach this conclusion. In contrast, our analysis reveals a counter-intuitive result: Despite a seemingly strong and statistically significant anchoring bias in most macroeconomic survey series, adjusting forecasts for the seemingly apparent bias leads to no systematic forecast improvements. Decomposing the anchoring bias test statistic provides an explanation for this puzzling result: the test itself is biased. Testing solely against univariate time series information the anchoring bias test neglects the possibility that analysts may provide superior forecasts by using a richer information set than just the univariate time series itself. Our empirical results support this explanation, revealing for a broad range of macroeconomic series that efficiency - rather than inefficiency - is producing the large "anchoring bias" coefficients. By arranging a "horse race" between survey and model

\footnotetext{
${ }^{2}$ See e.g. Pesando (1975), and Mullineaux (1978) Pearce and Roley (1985), Aggarwal et al. (1995), and Schirm (2003).

${ }^{3}$ The most recent study, Schirm (2003), finds only for small number of investigated series some bias. However his results partly contradict the findings of Aggarwal et al. (1995) obtained on a different sample.
} 
forecasts we document that analysts' forecasts aggregate more valuable information than contained in the historical time series and are therefore quite efficient. This forecast comparison is a distinctive contribution to the existing forecast quality literature. While previous studies assumed efficiency, we are the first to hypothesize inefficiency. Rejecting this hypothesis provides evidence in favor of efficient information processing by analysts. Our more general approach allows us to address the more interesting question whether analyst forecasts represent the best available information aggregate instead of testing whether one single piece of information was incorrectly incorporated.

Our analysis proceeds in five steps. First we replicate the anchoring bias test of Campbell and Sharpe (2009). However, we use a much broader set of macroeconomic indicators, allowing for a more comprehensive analysis. More importantly, we use a much longer sample period to facilitate out-of-sample tests. This "dynamic" analysis, i.e. testing on a rolling-window and correspondingly adjusting forecasts out-of-sample, enables us to build on the exact information flow, i.e. to consider only information available to market participants at a given point in time. Hence, our procedure avoids a look-ahead bias. This is of particular importance when we adjust the data for the anchoring bias, because only this real-time proceeding ensures a realistic comparison of unadjusted and adjusted data. In contrast, Campbell and Sharpe's analysis (which we call "static") is based on a single in-sample regression and a corresponding adjustment would incorporate a potentially severe look-ahead bias.

If the highly significant anchoring coefficients would stem from a cognitive bias, then adjusting the original survey forecasts must yield substantial improvements in forecast quality. Surprisingly, despite highly significant anchoring coefficients we can hardly find any significant improvements in forecast quality when adjusting for this seemingly apparent bias. Only when we allow for a look-ahead bias, i.e. for the statical estimation and adjustment, we find some modest improvements. More importantly and even more disturbingly, we can find 
virtually no improvements of forecast quality for the dynamically estimated anchoring coefficients, which avoid a look-ahead bias. Only for 2 out of 23 series we can find statistically significant improvements, but for another 2 series forecast quality significantly worsens through the adjustment. Overall, we have to conclude that nothing is gained by adjusting forecasts, despite highly significant anchoring test coefficients.

In order to explain this puzzling result we inspect in a third step the mechanics of the anchoring bias test. Most importantly, the anchoring bias test implicitly assumes a univariate time series framework. This creates a substantial problem since it neglects other information which most likely alters rational forecasts. In particular, we show that the overall test statistic can be decomposed into two components: The first component captures inefficient processing of univariate time series information, possibly due to anchoring. The second component, however, captures superior information processing abilities of analysts, supposedly due to using a richer information set. Hence, large and significant anchoring coefficients can not only arise when analysts face a cognitive bias but also when they correctly incorporate additional information in their predictions and therefore outperform time series forecasts. This suggests that neglecting other information may be responsible for the misleading anchoring bias test results. In fact, in line with previous research on the properties of stock market analysts' forecasts, ${ }^{4}$ we find that macroeconomic survey forecasts substantially outperform optimized time series forecasts. Overall, this analysis shows that the anchoring bias test is biased itself. Large coefficients could be just due to efficient - rather than inefficient information processing.

Outperforming optimal univariate time-series forecasts implies that analysts have to use some additional information while generating their forecast. In fact, in a fourth step, we provide

\footnotetext{
${ }^{4}$ For example, it has long been argued that financial analysts provide more accurate earnings forecasts than univariate time series models because analysts use a broader information set than just the univariate time series of historical earnings. For earnings forecasts this enlarged information set presumably includes, among other things, macroeconomic information. See, e.g., Brown (1993) and Brown et. al. (1997).
} 
evidence supporting the view that macroeconomic analysts use a much broader information set than just the univariate time series. In particular, we find that a substantial part of the forecast improvement analysts achieve over time series models can be explained by other macroeconomic data. This result suggests that analysts draw on several other macroeconomic indicators. We find that in particular those macroeconomic figures that are identified to be the most "important" ones by Gilbert et. al. (2010), i.e. those with substantial information content and those being released early in the monthly release cycle seem to contribute. Consequently, analysts seem to be rather efficient information processors pooling a large amount of valuable information.

Fifth, we quantify the relative contributions of the "inefficiency" and the "additional information" component to the overall anchoring bias test coefficient. Our results suggest that for the majority of significantly biased forecast series, the "additional information" component accounts for more than half of the overall anchoring bias coefficients' size. This explains the puzzling result that almost all survey forecasts seem to be severely anchoring biased while an adjustment does not lead to improvements.

Overall, our analysis yields an astonishing result. Rather than detecting inefficiencies in U.S. macroeconomic survey forecasts we find strong evidence for superior information processing abilities of analysts. The highly significant anchoring bias test results are not due to a cognitive bias of analysts, but result from their superiority compared to time series models. For every single macroeconomic series analysts easily outperform the out-of-sample forecasts of dynamically optimized time series models. This strongly indicates that survey forecasts aggregate additional information beyond the univariate time series data, in particular, other currently released macroeconomic figures. Obviously, it is extremely difficult if not impossible to adequately model the entire available information set and to come up with a better forecasting model. Therefore, we have to conclude that survey forecasts are still the 
best available approximation of market participants' expectations. Moreover, our analysis shows that testing for a specific bias such as anchoring by exclusively focusing on univariate time series properties is dangerous since it neglects the ability of analysts to aggregate additional information. Overall, our findings suggest that anchoring does not constitute any problem for earlier information processing studies building on survey forecasts.

With this study we contribute to different strands of literature. Our results directly add to the scarce literature analyzing possible biases in macroeconomic forecasts by showing that analysts' forecasts are the most comprehensive and efficient information aggregates. Consequently they best represent market participants' expectations regarding upcoming macroeconomic releases. Moreover, our findings have important implications for a broad range of studies relying on macroeconomic survey forecasts in order to extract unanticipated information components in scheduled releases (e.g. Andersen et al. (2003), Green (2004), Bernanke and Kuttner (2005), Hautsch and Hess (2007), Evans and Lyons (2008) to name just a few). Furthermore, since the anchoring bias adjusted forecast is basically a weighted combination of the survey forecast and an autoregressive model we contribute to the area of forecast combination in which currently no results concerning monthly macroeconomic survey forecasts are available.

The remainder of the study is organized as follows. In section 1 we briefly delineate the anchoring bias test and introduce our framework for the evaluation of analysts' forecasts. Section 2 describes the data and their properties. Section 3 provides the empirical results and section 4 concludes. 


\section{Methodology}

The basic assumption of the anchoring bias test ${ }^{5}$ is that the MMS survey forecast $\left(F_{t}\right)$ is a linear combination of an unbiased forecast for the next month's actual, $E\left[A_{t}\right]$, and an average of already released values for the $\bar{h}$ previous months:

$$
F_{t}=\lambda \cdot E\left[A_{t}\right]+(1-\lambda) \cdot A_{h}^{-}
$$

The unbiased estimator for next month's actual already incorporates all available information efficiently. The inclusion of additional past information is redundant and therefore $\lambda$ should be one. A value of $\lambda$ significantly smaller than one would suggests anchoring, i.e. putting too much weight on previously released values in comparison to an unbiased estimator.

Since the unbiased estimator is unobservable a direct estimation of equation (1) is not feasible. It can be shown that an indirect estimation of $\lambda$ is possible by means of (2) (see Appendix A for a derivation):

$$
S_{t}=\gamma \cdot\left(F_{t}-A_{h}^{-}\right)+\eta_{t}, \quad \text { with } \gamma \equiv \frac{(1-\lambda)}{\lambda}
$$

where $S_{t}$ denotes the unanticipated news component defined as actual minus forecast ${ }^{6}$. On the one hand, $\gamma>0$ would indicate anchoring, i.e. $\lambda<1$. On the other hand, there is no economically plausible explanation for $\gamma<0$, i.e. $\lambda>1$. Nevertheless, significant negative coefficients imply partly predictable surprises. Following, we might be able to improve forecast quality even in cases in which the anchoring bias test leads to results contradicting its purpose.

\footnotetext{
${ }^{5}$ Campbell and Sharpe (2009)

${ }^{6}$ Although equation (2) does not include a constant we always include one in the estimation.
} 
Equation (1) suggests that the unbiased estimate $E\left[A_{t}\right]$ is compounded of the survey based forecast and the anchor:

$$
E\left[A_{t}\right]=\frac{F_{t}}{\lambda}-\frac{(1-\lambda)}{\lambda} \cdot A_{h}=(1+\gamma) \cdot F_{t}-\gamma \cdot A_{h}^{-}
$$

Equation (3) in connection with $\gamma$ estimated on the basis of (2), the original forecast data can be adjusted for the anchoring induced bias. These adjusted forecasts serve as central input variables for our forecast quality comparison tests to determine the economical significance of the anchoring bias. We perform two different adjustments. First, to evaluate the in-sample impact of the anchoring bias we estimate (2) over the entire sample period and adjust the forecasts retrospectively. Additionally, to avoid an in-sample look-ahead bias, we perform a dynamic adjustment by means of a rolling estimation of (2). Given the current coefficient we adjust the next forecast in a way market participants would have been able to adjust the data. Since this approach represents an implementable strategy it has to be taken as the real test of the anchoring bias' impact.

To analyze the implicit time series framework underlying the anchoring bias test we assume that $A_{t}$ follows some $\operatorname{ARMA}(\mathrm{p}, \mathrm{q})$ process, a fairly general representation. Moreover we suppose that analysts use a corresponding $\operatorname{ARMA}(\mathrm{p}, \mathrm{q})$ model to generate forecasts. However, we believe that analysts do not restrict themselves to looking at historical time-series information. Instead we suppose that they possess some additional information $Z_{t}$ useful to predict the innovation $e_{t}$ in $A_{t}$, e.g., from inspecting other macroeconomic announcements or simply from reading the daily press. Based on these considerations we show that $\gamma$ in (2) can be written as (see Appendix B) 


$$
\hat{\gamma}=\frac{\operatorname{Cov}\left(e_{t}, x_{t-1}^{\prime}\right)+\operatorname{Cov}\left(y_{t-1}^{\prime}, x_{t-1}^{\prime}\right)-\operatorname{Cov}\left(Z_{t}, x_{t-1}^{\prime}\right)+\operatorname{Cov}\left(e_{t}, Z_{t}\right)-\operatorname{Var}\left(Z_{t}\right)}{\operatorname{Var}\left(x_{t-1}^{\prime}\right)+\operatorname{Var}\left(Z_{t}\right)+2 \cdot \operatorname{Cov}\left(Z_{t}, x_{t-1}^{\prime}\right)} .
$$

To separate the part of $\gamma$ driven by the additional information set measured by $Z_{t}$ we decompose $\hat{\gamma}$ into two parts

$$
\hat{\gamma}_{1}=\frac{\operatorname{Cov}\left(y_{t-1}^{\prime}, x_{t-1}^{\prime}\right)+\operatorname{Cov}\left(e_{t}, x_{t-1}^{\prime}\right)}{\operatorname{Var}\left(x_{t-1}^{\prime}\right)+\operatorname{Var}\left(Z_{t}\right)+2 \cdot \operatorname{Cov}\left(Z_{t}, x_{t-1}^{\prime}\right)}
$$

and

$$
\hat{\gamma}_{2}=\frac{\operatorname{Cov}\left(e_{t}, Z_{t}\right)-\operatorname{Var}\left(Z_{t}\right)-\operatorname{Cov}\left(Z_{t}, x_{t-1}^{\prime}\right)}{\operatorname{Var}\left(x_{t-1}^{\prime}\right)+\operatorname{Var}\left(Z_{t}\right)+2 \cdot \operatorname{Cov}\left(Z_{t}, x_{t-1}^{\prime}\right)}
$$

with

$$
\begin{aligned}
& y_{t-1}^{\prime} \equiv \sum_{j=1}^{\infty}\left(\beta_{j}-\hat{\beta}_{j}\right) \cdot e_{t-j} \\
& x_{t-1}^{\prime} \equiv \sum_{j=1}^{\infty} \hat{\beta}_{j} \cdot e_{t-j}-\frac{1}{h} \sum_{i=1}^{h}\left(e_{t-i}+\sum_{j=1}^{\infty} \beta_{j} \cdot e_{t-j-i}\right)
\end{aligned}
$$

$\hat{\gamma}_{1}=0$ if $\operatorname{Cov}\left(y_{t-1}^{\prime}, x_{t-1}^{\prime}\right)=0$, i.e., if analysts' estimates $\hat{\beta}_{j}$ are unbiased $\left(\hat{\beta}_{j}=\beta_{j} \forall j\right.$ implying in this case $\left.y_{t-1}^{\prime}=0\right)$ and if, at the same time, $\operatorname{Cov}\left(e_{t}, x_{t-1}^{\prime}\right)=0$. Since $x_{t-1}^{\prime}$ contains exclusively time series information up to time t-1 it should not contain predictive power to explain the innovation. If $x_{t-1}^{\prime}$ would allow to predict the innovation $e_{t}$, then "old" time series information would yield a more precise forecast than the survey forecast. In this case analysts' forecast (or the models they use) would be inefficient. Therefore, $\hat{\gamma}_{1}$ captures inefficiencies in analysts' forecasts. 
Since $x_{t-1}^{\prime}$ only consists of past innovations of the actual generating process it should at best be weakly correlated with $Z_{t}$. Furthermore, if analysts have superior forecasting abilities compared to the optimal time series model the correlation between $Z_{t}$ and $e_{t}$ should be positive. Consequently, if $\operatorname{Cov}\left(e_{t}, Z_{t}\right)>\operatorname{Var}\left(Z_{t}\right)+\operatorname{Cov}\left(Z_{t}, x_{t-1}^{\prime}\right)$ this suggests that a positive part of the anchoring coefficient $\gamma$ is driven by the additional information amount used by the surveyed analysts.

Since additional information, $Z_{t}$, is not directly observable we have to use a proxy measure. The basic idea is to generate an optimal univariate time-series forecast to extract $Z_{t}$ as the residual from the MMS survey forecast. First, we estimate an "optimal" ARIMA model for the actual. We select the optimal order of differencing $d$ according to a Phillips-Perron test. Then we estimate the model for all combinations of $p=0, \ldots, 6$ and $q=0,1$. We chose the best fitting model according to Bayes' information criterion (BIC) among those models providing residuals that are not serially correlated. Based on this selection procedure, we obtain an "optimal" time series model to describe the actual. The generated residuals of this model serve as proxy measure for the innovation of the actual generating process $\left(\varepsilon_{t}\right)$, i.e., the component in $A_{t}$ which is not predictable from historical univariate time series information.

Now we analyze survey forecasts $F_{t}$, applying a distributed lag model corresponding to the optimal ARIMA specification of actual, i.e. we regress the (differenced) forecasts $F_{t}$ on $\mathrm{p}$ lags of $A_{t}$ and q lags of $\hat{e}_{t}$. The residuals of this estimation serves as approximations for $Z_{t}$, i.e., the component in survey forecasts $F_{t}$ which cannot be traced back to past observed actuals. 
To rule out the possibility that our proxy for the additional information, $Z_{t}$, just picks up noise and to answer the question where analysts' outperformance comes from we analyze how $Z_{t}$ is related to information available at the time when analysts produce their forecasts. For this purpose we estimate the following model:

$$
Z_{t}=\alpha+\beta M_{t}+\varphi_{t}
$$

where $Z_{t}$ denotes the approximated additional information component in survey forecasts and $M_{t}$ a vector containing the available macroeconomic information set for the 23 considered indicators seven days prior to an announcement. Using a stepwise regression approach allows us to determine whether $Z_{t}$ is an inappropriate proxy for additional information or whether it is related to other macroeconomic news.

Finally we quantify the contribution of the "additional information" and the "inefficiency" component to the overall anchoring bias coefficient. Based on our theoretical considerations including equation (5) and (6) a partition is feasible and we can conclude whether irrationality or information efficiency drives the anchoring bias test results.

\section{Data Description}

We use a comprehensive data set comprising 23 well known macroeconomic indicators. Table 1 lists the series along with the abbreviations used in the following sections, their availability during the sample periods and the respective reporting unit. Medians of analysts' forecasts for these macroeconomic data are obtained from MMS and Action Economists ${ }^{7}$. As

\footnotetext{
${ }^{7}$ Each Friday, MMS polls analysts' forecasts of macroeconomic figures to be released during the following week. Survey responses are received over a three- to four-hour period every Friday morning via fax or phone. The results of the survey are published at around 1:30 PM EST. In September 2003 MMS was acquired by Informa. However, the original MMS survey was conducted until mid of December 2003. For the time after December 2003 we use forecasts provided by Action Economics (AE). Although AE is not MMS' legal
} 
a robustness check we use Bloomberg and Reuters forecasts. Since the results are virtually identical we do not report them. Whenever available, we use ALFRED vintage data to measure actual announced values. ${ }^{8}$ Otherwise announced values provided by the survey agencies are used.

Table 2 shows sample means $(\mu)$ and standard deviations $(\sigma)$ for the 23 considered indicators (actuals, forecasts, and surprises). Sample means of the surprises are close to zero for most indicators implying that the forecasts are unbiased if not conditioned on a specific information set. Moreover, except for a few series (in particular, HE) the standard deviations of surprises are substantially smaller than the standard deviations of actual implying positive correlations of the actual and the forecast. ${ }^{9}$

\section{Empirical Results}

Our empirical analysis proceeds in four steps. First, we perform both in- and out-of-sample anchoring tests for a broad range of macroeconomic series. Given the bias estimates, we analyze in a second step whether analysts' forecasts can be improved by adjustments for anchoring. Then in a third step, we evaluate the analysts' forecasting abilities in comparison to optimally selected univariate time series models. Furthermore, to explain analysts' outperformance we analyze which additional information are processed in their forecasts. Finally, we decompose the estimated anchoring coefficients $\hat{\gamma}$ into an "inefficiency" component $\hat{\gamma}_{1}$ and an "additional information" component $\hat{\gamma}_{2}$ and evaluate their relative contributions to determine the factor driving the anchoring bias test results.

successor in terms of content it is, because most of the former MMS employees responsible for the survey founded $\mathrm{AE}$ after the takeover. In the following we always name the median forecast time series MMS forecasts, although it is continued with AE forecasts.

${ }^{8}$ The Federal Reserve Bank of St. Louis provides excess to a broad set of US macroeconomic data in their online database called ArchivaL Federal Reserve Economic Data.

${ }^{9}$ The correlation between $A_{t}$ and $F_{t}$ is positive if $V\left[S_{t}\right]<V\left[A_{t}\right]+V\left[F_{t}\right]$. 


\section{a. Anchoring tests results}

We start with a "static" or in-sample test design and estimate equation (2) on the full sample for three different specifications of $\bar{h}$, where $\bar{h}=1$ corresponds to anchoring on the last month's actual only and $\bar{h}=2$ or 3 to anchoring on the mean of the two or three previously announced actual values, respectively. Since the static test involves a serious lookahead-bias we perform a "dynamic" analysis in addition, estimating the anchoring coefficients on a rolling window with a fixed length of 10 years.

Table 3 reports results for the static as well as for the dynamic test. Regarding the static tests, we report the optimal $\bar{h}$, i.e. which regression specification performed best according to the Bayes' information criterion (BIC), along with the corresponding anchoring bias coefficient $\hat{\gamma}$. These results suggest that in about two thirds of the cases analyst use an average and not a single value as anchor. According to the test results survey forecasts for 18 out of the 23 macroeconomic series are significantly biased. However, for two of these series we obtain significantly negative coefficients which could hardly be explained by anchoring. Moreover, the large variation in the estimated coefficients suggests substantially different degrees of anchoring. For factory orders (FO), for example, this would imply that analysts put about $4 \%$ weight on last month's release and about $96 \%$ on the expected value, i.e., the unbiased forecast. In contrast, for consumer confidence (CC) it seems that the unbiased estimator and the previously released actual enter the MMS forecast with approximately equal weights.

Results of the dynamic anchoring tests are given in Table 3 as well. For simplicity we only report the most frequently observed optimal $\bar{h}$ along with means and the standard deviations of the $\hat{\gamma} \mathrm{s}$ estimated on rolling windows of 10 years length. For most macroeconomic series the mean dynamic $\hat{\gamma}$ are largely comparable to their static $\hat{\gamma}$ counterparts, in particular, for the series which exhibit a significant static $\hat{\gamma}$. Surprisingly, the standard deviations of the 
dynamic $\gamma$ estimates are rather large and indicate a substantial variation over the sample. For example, for CC we obtain a mean of 0.922 and a standard deviation of 0.365 , stemming from a range of dynamic $\hat{\gamma} \mathrm{s}$ (not reported) of -0.306 to 1.434 . In fact, many series exhibit a substantial time variation in the $\hat{\gamma}$ coefficients.

Although the dynamic test results appear to be slightly weaker overall they are akin to the static test outcomes. For both static and dynamic we get sizable $\hat{\gamma}$ coefficients for most of the macroeconomic forecast series indicating substantial anchoring. At first sight this suggests partly predictable surprises and portends a poor quality of the frequently used MMS forecasts. Consequently this questions their appropriateness as proxy measures for market participants' expectations.

\section{b. Can anchoring adjustments improve analysts' forecasts?}

Given the highly significant and sizable anchoring coefficients we would expect that analysts' forecast can be substantially improved by adjusting them according to equation (3). Results are given in Table 4. First, we compute in-sample adjustments applying the estimated static $\gamma$ coefficients. Then, to evaluate the real economical impact, we apply dynamic $\gamma$ coefficients. To adjust the forecast for period $t$ we use the dynamic $\gamma$ coefficients estimated on information up to time $t$ - 1 . In contrast to the static adjustments, this avoids a look-ahead bias. For both static and dynamic adjustments we report the change in root mean squared forecast errors ( $\triangle \mathrm{RMSFE}$ ) resulting from these adjustments. Negative values indicate that the RMSFE of the adjusted MMS forecast is smaller than the unadjusted one, i.e. that the anchoring bias adjustment improves forecasts. To test whether these improvements are significant, we run Diebold and Mariano (1995) tests on differences in mean squared errors 
(MSE). ${ }^{10}$ Since macroeconomic analysts, in contrast to stock market analysts, have no incentives to issue systematic overoptimistic or pessimistic forecasts the assumption of a quadratic loss function implied by the MSE is uncritical.

By construction, the static (or in-sample) adjustments cannot yield a larger RMSFE of the adjusted series. Nevertheless, the improvements are rather small. We observe a reduction of $8.38 \%$ at best. Moreover, the Diebold Mariano tests find that only about $60 \%$ of the significantly biased forecast series can be improved. This is somewhat surprising since the static anchoring tests make use of forward looking information. Naturally, one would expect significant forecast changes whenever we get a significant anchoring test coefficient, at least for the static case.

The results of dynamic adjustments are much worse. When we adjust forecasts dynamically, i.e. without using forward looking information, almost no improvements can be obtained. There are only two exceptions, CC and DGO for which we obtain significantly improved forecasts according to the Diebold-Mariano test on differences in MSE. These correspond to a reduction in RMSFEs of nearly $8 \%$ for $\mathrm{CC}$ and less than $6 \%$ for DGO. On the other hand, we observe also two cases with significantly worsening forecast errors, i.e. NF and TRD. For all other series, changes in forecast errors are insignificant though large in some cases. For example, we observe the largest though insignificant forecast error change for RS, worsening the series' RMSFE by around $15 \%$. Since the dynamical adjustment best represents market participants' approach to correct for the cognitive bias our results provide strong evidence against the economical significance of the anchoring bias.

Moreover, note that the size of the anchoring coefficient is at best loosely related to the improvements. For instance the durable goods orders bias coefficient is 0.398 and results in

\footnotetext{
${ }^{10}$ The test we apply includes the small sample adjustment of Harvey, Leybourne and Newbold (1997).
} 
an RMFSE improvement of about $4.6 \%$. In contrast the personal consumption expenditures anchoring bias coefficient is only 0.189 and leads to a considerable larger RMFSE reduction of about $7 \%$. This odd pattern provides evidence that the anchoring bias test results might be misleading, i.e., a sizable $\hat{\gamma}$ does not necessarily lead to large forecast improvements.

\section{c. Incremental forecast improvement over time series models}

Our theoretical analysis provides a possible - though disturbing - explanation for the disconnection of forecast improvements and $\hat{\gamma}$-coefficients. Equation (6) suggests that we may find a significant anchoring bias simply because analysts provide sophisticated forecasts by incorporating additional information beyond the univariate time-series information. This is definitely not unreasonable. For example, just by reading the current newspapers, analysts can process other contemporaneous business news. Technically speaking, $\gamma$-coefficients may just reflect that analysts can forecast part of the innovation in the data generating process, i.e. part of the change from the last month's actual unpredictable with univariate time-series information, by drawing on a richer information set. This would imply that survey forecasts are quite efficient - not inefficient as indicated by the anchoring bias test results.

To analyze this issue, we compare analysts' median forecasts $F_{t}$ for a given month $t$ with an “optimal" univariate time series forecast $F_{t}^{T S}$. To obtain an optimal forecast series without a look-ahead bias, we estimate various time series models using a rolling window. More precisely, for each point in time $t-1$ we estimate a broad range of different $\operatorname{ARIMA}(\mathrm{p}, \mathrm{d}, \mathrm{q})$ specifications (i.e. all combinations of $\mathrm{p}=1, \ldots, 6, \mathrm{~d}=0,1$, and $\mathrm{q}=0,1$ ) using the last 10 years of data. Out of these we select the best fitting model according to the BIC. The estimated coefficients of this best fitting model are then used to produce a one-period-ahead time-series forecast $F_{t}^{T S}$ for period $t$. Then we shift the estimation window by one observation and 
repeat the procedure to obtain a forecast for the next period. Concatenating these one-stepahead forecasts, we obtain a time series of optimal forecasts.

Summary statistics for this optimal forecasts series are given in Table 5. The first column reports the parameters $\mathrm{p}, \mathrm{d}, \mathrm{q}$ for the most frequently best fitting ARIMA model. For example, for $\mathrm{CC}$ a specification with $\mathrm{p}=1, \mathrm{~d}=0$ and $\mathrm{q}=0$, i.e. a simple $\mathrm{AR}(1)$ model, turns out to provide the best fit in most cases. An even simpler model emerges for ISM: the most frequently optimal specification is $\mathrm{p}=0, \mathrm{~d}=1$ and $\mathrm{q}=0$, i.e. a model in first differences including solely a constant term. Thus for ISM the most frequently optimal model is a random walk with drift. Similarly for the majority of the other series the optimal model is rather simple. In most cases we find an $\operatorname{AR}(1), \operatorname{MA}(1)$, or $\operatorname{ARMA}(1,1)$ processes (after first differencing) to be optimal. Only a few series call for second or third order processes.

Note that our time series of one-step-ahead forecasts $F_{t}^{T S}$ estimated on a rolling window exploits the historical time series information available at any point in time most efficiently, but at the same time, avoids a look-ahead bias. In this sense it provides a benchmark for analysts' forecasts. Anchoring is equivalent to overestimating the influence of past observations, e.g. using a larger than optimal first-order autoregressive parameter when applying an AR(1) model. Hence, if analysts produce forecasts that are more or less strongly anchoring biased we would expect that an efficiently estimated time series model (avoiding this bias) outperforms analysts' forecasts. However, this only holds if the underperformance induced by the anchoring bias outweighs the overperformance resulting from the use of a broader information set.

This is definitely not the case. Columns 2 and 3 of Table 5 provide a comparison of forecast errors (RMSFE) of our out-of-sample time series forecasts and analysts' predictions. Column 5 reports the relative difference. For every single macroeconomic series the RMSFE of 
analysts' forecasts is smaller, for most series by more than $20 \%$ implying economically significant better forecasts. To evaluate the statistical significance of these forecast improvements, we use again a Diebold-Mariano test with small sample adjustment. For 20 out of the 23 series we find significant differences in MSE. For the vast majority of macroeconomic series analysts' forecasts significantly outperform the time series forecasts. For the remaining three series, i.e. core PPI, HS, and CS, analysts' forecasts have a smaller error as well, though the differences are statistically insignificant.

Overall, for none of the macroeconomic series our sophisticated time-series models outperform analysts' forecasts. Hence, in line with previous research on stock analysts' forecast performance (see e.g. Brown et al. (1987)), our estimation results clearly show that analysts provide superior forecasts in comparison to optimally selected univariate time series models.

Outperforming a model which optimally exploits univariate time series information can only stem from using a richer information set. To extract the forecast component which is unrelated to historical announcements (i.e., $Z_{t}$ ) we use the procedure described in section 1 . Based on a distributed lag model, we decompose $F_{t}$ into a component explained by historical time series information and a residual $\hat{Z}_{t}$. Now, this residual could just represent noise picked up by analysts when producing their forecasts. In this case $\hat{Z}_{t}$ would not help to predict $A_{t}$, or more precisely, would be uncorrelated with our estimate of the innovation in $A_{t}$, i.e., $\hat{e}_{t}$.

Correlations of $\hat{Z}_{t}$ and $\hat{e}_{t}$ are reported in Table 6. Most importantly, we find solely positive and highly significant correlations of $\hat{Z}_{t}$ and $\hat{e}_{t}$. This strongly suggests that $\hat{Z}_{t}$ represents not just noise being picked up somehow by analysts. In contrast, the additional information component in analysts' forecasts is able to predict some part of the innovation in 
announcements. Since our approximated innovation $\hat{e}_{t}$ constitutes the unpredictable part in an announcement after employing optimally univariate time-series information, the high correlation of $\hat{Z}_{t}$ and $\hat{e}_{t}$ also suggests that analysts' superior forecasting abilities stem from the incorporation of valuable additional information. Again, this finding is in line with studies analyzing stock analysts' forecast performance. For instance Fried and Givoly (1982) document that stock analysts' outperformance over time-series models is based on autonomous, i.e. additional information.

One potential source of valuable additional information are other macroeconomic news. Due to interrelations between macroeconomic indicators it is quite plausible that analysts utilize these releases in their forecast generation process. Therefore, other macroeconomic news should be able to, at least partly, explain the additional information approximated by $\hat{Z}_{t}$. Especially indicators released early in the cycle and those with large information content about the state of the economy should be useful (Gilbert et. al. 2010). As described in Section I we regress $\hat{Z}_{t}$ on all macroeconomic information available seven days prior to the announcements using a stepwise regression approach to identify the most influential indicators. Table 7 shows the regression results for selected indicators. Table 8 provides an overview for all indicators showing how many other indicators contribute to the explanation of $\hat{Z}_{t}$ in column (1). Column (2) reports the associated $\mathrm{R}^{2}$ and the last column shows how often the indicator is useful to explain $Z_{t}$ of other macroeconomic series. Consumer Confidence for instance helps to explain $Z_{t}$ of 10 other macroeconomic series, i.e. is contained in the best model for 10 indicators. The results provide strong evidence that additional macroeconomic information can partly explain analysts' outperformance compared to optimized univariate time-series models. Depending on the indicator, between $7.0 \%$ (CPI) 
and almost $81 \%$ (PCE) of the variation in $\hat{Z}_{t}$ can be explained by other macroeconomic information. On average, R-squares amount to 36\%. Furthermore, column (3) reveals that the most influential indicators are those which are released relatively early and which are commonly viewed to be good indicators of current or future economic activity. Consequently, we find ISM, CC, RS, NFP and UN to be the most important components of the additional macroeconomic information set. ISM for instance contributes in 14 out of 23 cases to the explanation of $\hat{Z}_{t}$.

Moreover, our results indicate that analyst process even more information beyond a broad set of macroeconomic news, probably including data which are not easily accessible via regular databases This suggests that their contribution as information intermediaries is valuable. Nevertheless, we cannot rule out that analysts' forecasts may still contain some behavioral bias. At least, our results suggest that the advantage of using a richer information set by far exceeds possible disadvantages associated with behavioral biases.

\section{d. Decomposition of anchoring test results}

Coming back to the question why the anchoring test produces so significant results, the high correlations of $\hat{Z}_{t}$ and $\hat{e}_{t}$ may provide an answer. According to equations (4) to (6) we can decompose the anchoring coefficient $\hat{\gamma}$ into an "inefficiency" component $\hat{\gamma}_{1}$ and an "additional information" component $\hat{\gamma}_{2}$. Table 9 provides statistics on $\hat{\gamma}_{1}$ and $\hat{\gamma}_{2}$. For comparison, static as well as dynamic $\gamma$-estimates are displayed in columns 1 and 2, respectively. Column 3 shows the approximated $\hat{\gamma}$ calculated on the basis of equation (4). In addition, columns 4 and 5 show the two components of $\hat{\gamma}$, i.e., the "inefficiency" component $\hat{\gamma}_{1}$ and the "additional information" component $\hat{\gamma}_{2}$. 
The results clearly show that the additional information component $\hat{\gamma}_{2}$ is largely responsible for a substantial part of the overall $\hat{\gamma}$. Considering the macroeconomic series with a significantly positive anchoring bias coefficient, we find that in 11 out of 16 cases $\hat{\gamma}_{2}$ accounts for more than $50 \%$ of $\hat{\gamma}$. In two additional cases $\hat{\gamma}_{2}$ accounts for more than $25 \%$.

The theoretical decomposition analysis has already shown that the anchoring test can produce biased results due to the "additional information" component it contains. ${ }^{11}$ The empirical results now show that this "additional information" component is quite large for most macroeconomic series. This clearly indicates that the test itself includes a bias which is substantial.

These findings also provide an explanation for the puzzling forecast improvement results. If the anchoring bias test does not solely measure a cognitive bias, it is not surprising that controlling for such a bias cannot significantly change the quality of survey forecasts.

\section{Conclusion}

The anchoring bias test recently suggested by Campbell and Sharpe (2009) indicates that the survey forecasts for a broad range of US macroeconomic releases are severely biased. This irrationality implies that survey forecasts could be substantially improved when we control for the bias. Surprisingly, applying a dynamic test and adjustment procedure we find hardly any forecast improvements. Our theoretical analysis explains this puzzling empirical result: Focusing on the univariate time-series properties of announcements the anchoring test neglects the possibility that analysts draw on a more comprehensive information set. Given the univariate setting of the anchoring test, our "horse race" of survey forecasts against univariate time series model forecasts clearly shows that analysts have superior information

\footnotetext{
${ }^{11}$ An adjustment based solely on $\widehat{\gamma_{1}}$ leads to comparable results and is therefore not reported.
} 
processing abilities. Most likely, their outperformance is due to using a richer information set embracing more than just the univariate macroeconomic series. Obviously, analysts have access to a lot more information, for example, other related macroeconomic data or recent policy statements. We find that analysts use other macroeconomic information to generate their forecasts. Especially indicators released early in the month and those with much content about current and future economic activity are part of their information set.

Our empirical decomposition of the estimated anchoring bias coefficients shows that analysts' outperformance has a strong impact on the anchoring test. For the majority of significant anchoring tests, the "additional information" component explains more than half the size of the overall anchoring coefficient. This leads us to conclude that the anchoring test is highly misleading. In the majority of cases efficiency - not inefficiency -leads to the statistical significant results.

Given the strong bias in the test and the weak forecast improvements associated with anchoring adjustments, the economical significance of anchoring in macroeconomic surveys is more than questionable. Overall, our results suggest that there is no reason to question the results of earlier studies using the MMS macroeconomic forecasts.

An intriguing question for further research is therefore whether and to what extent macroeconomic analysts could outperform more sophisticated time series models. Naturally, a statistical model will never be able to capture the entire available information set. However, model based forecasts should be free of any cognitive bias. Yet, in order to obtain better forecasting models it is necessary to develop a better understanding of the factors driving the outperformance of analysts. While we cannot rule out with certainty that analysts' forecasts may contain some bias, our results clearly show that analysts' forecasts substantially 
outperform time series forecasts. Finally we have to conclude that survey forecasts provide the best available approximation of market participant's expectations. 


\section{Appendix A}

As stated the direct estimation of

$$
F_{t}=\lambda \cdot E\left[A_{t}\right]+(1-\lambda) \cdot A_{h}^{-}
$$

is not possible. However the estimation becomes feasible by means of the well known definition of the unanticipated news component of a macroeconomic release:

$$
S_{t}=A_{t}-F_{t}
$$

where $S_{t}$ denotes the unanticipated news component called surprise, $A_{t}$ the actual announced value of the macroeconomic indicator and $F_{t}$ the survey based forecast. Taking the expectation of equation (9) and rearranging it leads to:

$$
E\left[A_{t}\right]=F_{t}+E\left[S_{t}\right]
$$

Substituting $E\left[A_{t}\right]$ in (8) with (10) gives the model for the further investigation:

$$
E\left[S_{t}\right]=\frac{(1-\lambda)}{\lambda} \cdot\left(F_{t}-A_{h}^{-}\right)
$$

For reasons of clarity we define the slope coefficient in our model as:

$$
\gamma \equiv \frac{(1-\lambda)}{\lambda}
$$

Therefore the regression model for the test of the anchoring bias is given by ${ }^{12}$ :

$$
S_{t}=\gamma \cdot\left(F_{t}-A_{h}^{-}\right)+\eta_{t}
$$

\footnotetext{
${ }^{12}$ Although equation (13) does not include a constant we always include one in the estimation.
} 


\section{Appendix B}

Assume that $A_{t}$ follows an $\operatorname{ARMA}(\mathrm{p}, \mathrm{q})$ process without constant term, i.e.,

$$
A_{t}=b_{1} \cdot A_{t-1}+b_{2} \cdot A_{t-2}+\ldots+b_{p} \cdot A_{t-p}+e_{t}+c_{1} \cdot e_{t-1}+c_{2} \cdot e_{t-2}+\ldots+c_{q} \cdot e_{t-q}
$$

with i.i.d. $e_{t} \sim N\left(0, \sigma^{2}\right)$. Provided the process is stationary, it can be rewritten as

$$
A_{t}=\psi(L) e_{t} \quad \text { with } \psi(L)=\frac{1+c_{1} \cdot L+c_{2} \cdot L^{2}+\ldots+c_{q} \cdot L^{q}}{1-b_{1} \cdot L-b_{2} \cdot L^{2}-\ldots-b_{p} \cdot L^{q}}
$$

i.e. as an infinite MA process. For example, for an $\operatorname{ARMA}(1,1)$ we get $^{13}$

$$
A_{t}=e_{t}+\sum_{j=1}^{\infty} \beta_{j} \cdot e_{t-j} \quad \text { with } \beta_{j}=b_{1}^{j-1} \cdot c_{1}+b_{1}^{j}
$$

Moreover suppose that analysts use a corresponding $\operatorname{ARMA}(\mathrm{p}, \mathrm{q})$ model to generate forecasts.

However, suppose that analysts can obtain some additional information $Z_{t}$ useful to predict the innovation $e_{t}$ in $A_{t}$, e.g., from the inspection of other macroeconomic announcements released earlier. Assume that $\operatorname{corr}\left(e_{t}, Z_{t}\right) \neq 0$ and $\operatorname{corr}\left(e_{t-j}, Z_{t}\right)=0 \forall j \geq 1$. Then their forecasts may be written as

$$
F_{t}=\sum_{j=1}^{\infty} \hat{\beta}_{j} \cdot e_{t-j}+Z_{t}
$$

$$
\begin{aligned}
A_{t} & =e_{t}+c_{1} \cdot e_{t-1}+b_{1} \cdot A_{t-1} \\
& =e_{t}+\left(c_{1}+b_{1}\right) \cdot e_{t-1}+b_{1} \cdot c_{1} \cdot e_{t-2}+b_{1}^{2} \cdot A_{t-2} \\
& =e_{t}+\left(c_{1}+b_{1}\right) \cdot e_{t-1}+\left(b_{1} \cdot c_{1}+b_{1}^{2}\right) \cdot e_{t-2}+b_{1}^{2} \cdot c_{1} \cdot e_{t-3}+b_{1}^{3} \cdot A_{t-3} \\
& =e_{t}+\left(c_{1}+b_{1}\right) \cdot e_{t-1}+\left(b_{1} \cdot c_{1}+b_{1}^{2}\right) \cdot e_{t-2}+\left(b_{1}{ }^{2} \cdot c_{1}+b_{1}^{3}\right) \cdot e_{t-3}+\ldots \\
& =e_{t}+\sum_{j=1}^{\infty}\left(b_{1}^{j-1} \cdot c_{1}+b_{1}^{j}\right) \cdot e_{t-j} \\
& =e_{t}+\sum_{j=1}^{\infty} \beta_{j} \cdot e_{t-j} \quad \text { with } \beta_{j}=b_{1}{ }^{j-1} \cdot c_{1}+b_{1}{ }^{j}
\end{aligned}
$$


Substituting the above $\mathrm{MA}(\infty)$ representations of the ARMA(1,1) processes of $A_{t}$ and $F_{t}$ into the anchoring regression yields

$$
\begin{aligned}
& A_{t}-F_{t}=\gamma \cdot\left(F_{t}-\frac{1}{h} \sum_{i=1}^{h} A_{t-i}\right)+\eta_{t} \\
& \left(e_{t}+\sum_{j=1}^{\infty} \beta_{j} \cdot e_{t-j}\right)-\left(\sum_{j=1}^{\infty} \hat{\beta}_{j} \cdot e_{t-j}+Z_{t}\right) \\
& =\gamma \cdot\left(\left(\sum_{j=1}^{\infty} \hat{\beta}_{j} \cdot e_{t-j}+Z_{t}\right)-\frac{1}{h} \sum_{i=1}^{h}\left(e_{t-i}+\sum_{j=1}^{\infty} \beta_{j} \cdot e_{t-j-i}\right)\right)+\eta_{t} \\
& e_{t}+\left(\sum_{j=1}^{\infty}\left(\beta_{j}-\hat{\beta}_{j}\right) \cdot e_{t-j}\right)-Z_{t} \\
& =\gamma \cdot\left(\left(\sum_{j=1}^{\infty} \hat{\beta}_{j} \cdot e_{t-j}+Z_{t}\right)-\frac{1}{h} \sum_{i=1}^{h}\left(e_{t-i}+\sum_{j=1}^{\infty} \beta_{j} \cdot e_{t-j-i}\right)\right)+\eta_{t}
\end{aligned}
$$

Now, we can rewrite the anchoring bias regression as

$$
\begin{aligned}
& \underbrace{e_{t}+y_{t-1}^{\prime}-Z_{t}}_{y_{t}}=\hat{\gamma} \cdot \underbrace{\left(x_{t-1}^{\prime}+Z_{t}\right)}_{x_{t}}+\eta_{t} \\
& \text { with } y_{t-1}^{\prime} \equiv \sum_{j=1}^{\infty}\left(\beta_{j}-\hat{\beta}_{j}\right) \cdot e_{t-j} \\
& \text { and } x_{t-1}^{\prime} \equiv \sum_{j=1}^{\infty} \hat{\beta}_{j} \cdot e_{t-j}-\frac{1}{h} \sum_{i=1}^{h}\left(e_{t-i}+\sum_{j=1}^{\infty} \beta_{j} \cdot e_{t-j-i}\right) .
\end{aligned}
$$

Note that $y_{t-1}^{\prime}$ and $x_{t-1}^{\prime}$ collect past time series information, or more precisely, terms depending on past innovations $\varepsilon_{t}$ and (true and estimated) time series parameters $\left(\hat{\beta}_{j}\right.$ and $\beta_{j}$ ). In contrast, $\varepsilon_{t}$ captures the innovations (or residuals) of the announcement process, i.e. the component of an announcement which is unpredictable on the basis of past time series information. $Z_{t}$ is similar to a residual since it cannot be explained by past announcements. 
Hence $Z_{t}$ reflects deviations of analysts' forecasts from purely time series based forecasts, or the influence of "other information" (besides past announcements) on analyst' forecasts.

The coefficient $\hat{\gamma}$ of the anchoring regression is given by

$$
\begin{aligned}
\hat{\gamma} & =\frac{\operatorname{Cov}\left(x_{t}, y_{t}\right)}{\operatorname{Var}\left(x_{t}\right)} \\
& =\frac{\operatorname{Cov}\left(e_{t}+y_{t-1}^{\prime}-Z_{t}, x_{t-1}^{\prime}+Z_{t}\right)}{\operatorname{Var}\left(x_{t-1}^{\prime}+Z_{t}\right)} \\
& =\frac{\operatorname{Cov}\left(e_{t}, x_{t-1}^{\prime}\right)+\operatorname{Cov}\left(y_{t-1}^{\prime}, x_{t-1}^{\prime}\right)-\operatorname{Cov}\left(Z_{t}, x_{t-1}^{\prime}\right)+\operatorname{Cov}\left(e_{t}, Z_{t}\right)-\operatorname{Var}\left(Z_{t}\right)}{\operatorname{Var}\left(x_{t-1}^{\prime}\right)+\operatorname{Var}\left(Z_{t}\right)+2 \cdot \operatorname{Cov}\left(Z_{t}, x_{t-1}^{\prime}\right)}
\end{aligned}
$$

where the last line exploits the fact that $\operatorname{Cov}\left(Z_{t}, y_{t-1}^{\prime}\right)=0$ by construction.

We can split up this expression for the coefficient $\hat{\gamma}$ into two parts by collecting all terms in the numerator depending on $x_{t-1}^{\prime}$ and those depending on $Z_{t}$ :

$$
\begin{aligned}
& \hat{\gamma}_{1}=\frac{\operatorname{Cov}\left(y_{t-1}^{\prime}, x_{t-1}^{\prime}\right)+\operatorname{Cov}\left(e_{t}, x_{t-1}^{\prime}\right)}{\operatorname{Var}\left(x_{t-1}^{\prime}\right)+\operatorname{Var}\left(Z_{t}\right)+2 \cdot \operatorname{Cov}\left(Z_{t}, x_{t-1}^{\prime}\right)} \\
& \hat{\gamma}_{2}=\frac{\operatorname{Cov}\left(e_{t}, Z_{t}\right)-\operatorname{Var}\left(Z_{t}\right)-\operatorname{Cov}\left(Z_{t}, x_{t-1}^{\prime}\right)}{\operatorname{Var}\left(x_{t-1}^{\prime}\right)+\operatorname{Var}\left(Z_{t}\right)+2 \cdot \operatorname{Cov}\left(Z_{t}, x_{t-1}^{\prime}\right)}
\end{aligned}
$$

The first component $\hat{\gamma}_{1}$ captures the influence of (possibly biased) parameters $\hat{\beta}_{j}$, while the second component $\hat{\gamma}_{2}$ captures the influence of $Z_{t}$. 


\section{References}

Aggarwal, R., S. Mohanty, and F. Song (1995): Are Survey Forecasts of Macroeconomic Variables Rational?, Journal of Business, 68, 99-119.

Almeida, A., C. Goodhart, and R. Payne (1998): The Effects of Macroeconomic News on High Frequency Exchange Rate Behavior, Journal of Financial and Quantitative Analysis, 33, 383-408.

Andersen, T. G., T. Bollerslev, F. X. Diebold, and C. Vega (2003): Micro Effects of Macro Announcements: Real-Time Price Discovery in Foreign Exchange, American Economic Review, 93, 38-62.

Balduzzi, P., E. J. Elton, and T. C. Green (2001): Economic News and Bond Prices: Evidence from the U.S. Treasury Market, Journal of Financial and Quantitative Analysis, 36, 523543.

Bernanke, B. S. and K. N. Kuttner (2005): What Explains the Stock Market's Reaction to Federal Reserve Policy?, Journal of Finance, 60, 1221-1257.

Brown, L. D. (1993): Earnings forecasting research: its implications for capital markets research, International Journal of Forecasting, 9, 295-320.

Brown, L. D., R. L. Hagerman, P. A. Griffin, and M. E. Zmijewski (1987): Security Analysts Superiority Relative to Univariate Time series Models in Forecasting Quarterly Earnings, Journal of Accounting and Economics, 9, 61-87

Campbell, S. D., and S. A. Sharpe (2009): Anchoring Bias in Consensus Forecasts and Its Effect on Market Prices, Journal of Financial and Quantitative Analysis, 44, 369-390.

Diebold, F.X., and R. Mariano (1995): Comparing Predictive Accuracy, Journal of Business and Economic Statistics, 13, 253-265.

Elton, E. J. (1999): Expected Return, Realized Return, and Asset Pricing tests, Journal of Finance, 54, 1199-1220.

Evans, M. D. D., and R. K. Lyons (2008): How is macro news transmitted to exchange rates?, Journal of Financial Economics, 88, 26-50.

Flannery, M. J., and A. A. Protopapadakis (2002): Macroeconomic factors Do Influence Aggregate Stock Returns, Review of Financial Studies, 15, 751-782.

Fried, D., and D. Givoly (1982): Financial Analysts' Forecasts of Earnings - A Better Surrogate for Market Expectations, Journal of Accounting and Economics, 4, 85-107 
Gilbert, T., C. Scotti, G. Strasser, and C. Vega (2010): Why Do Certain Macroeconomic News Announcements Have a Big Impact on Asset Prices? Working Paper, University of Washington.

Gürkaynak, R. S., B. Sack, and E. Swanson (2005): The Sensitivity of Long-Term Interest Rates to Economic News: Evidence and Implications for Macroeconomic Models, American Economic Review, 95, 425-436.

Harvey, D., S. Leybourne, and P. Newbold (1997): Testing the equality of prediction mean squared errors, International Journal of Forecasting, 13, 281-291.

Hautsch, N., and D. Hess (2007): Bayesian Learning in Financial Markets - Testing for the Relevance of Information Precision, Journal of Financial and Quantitative Analysis, 42, 189-208.

Hautsch, N., D. Hess, and C. Müller (2010): Price Adjustment to News with Uncertain Precision, Working Paper, Centre for Financial Research, University of Cologne.

McQueen, G., and V. V. Roley (1993): Stock Prices, News, and Business Conditions, Review of Financial Studies, 6, 683-707.

Mullineaux, D. J. (1978): On Testing for Rationality: Another Look at the Livingston Price Expectations Data, Journal of Political Economy, 86, 329-336.

Muth, J. F. (1961): Rational Expectations and the Theory of Price Movements, Econometrica, $29,315-335$.

Pearce, D. K., and V. V. Roley (1985): Stock Prices and Economic News, Journal of Business, 58, 49-67.

Pesando, J. E. (1975): A Note on the Rationality of the Livingston Price Expectations, Journal of Political Economy, 83, 849-858.

Schirm, D. C. (2003): A Comparative Analysis of the Rationality of Consensus Forecasts of U.S. Economic Indicators, Journal of Business, 76, 547-561.

Tversky, A., and D. Kahneman (1974): Judgment under Uncertainty: Heuristics and Biases, Science, 185, 1124-1131.

Urich, T.,and P. Wachtel (1984): The Effects of Inflation and Money Supply Announcements on Interest Rates, Journal of Finance, 39, 1177-1188. 
Table 1: Indicator Overview

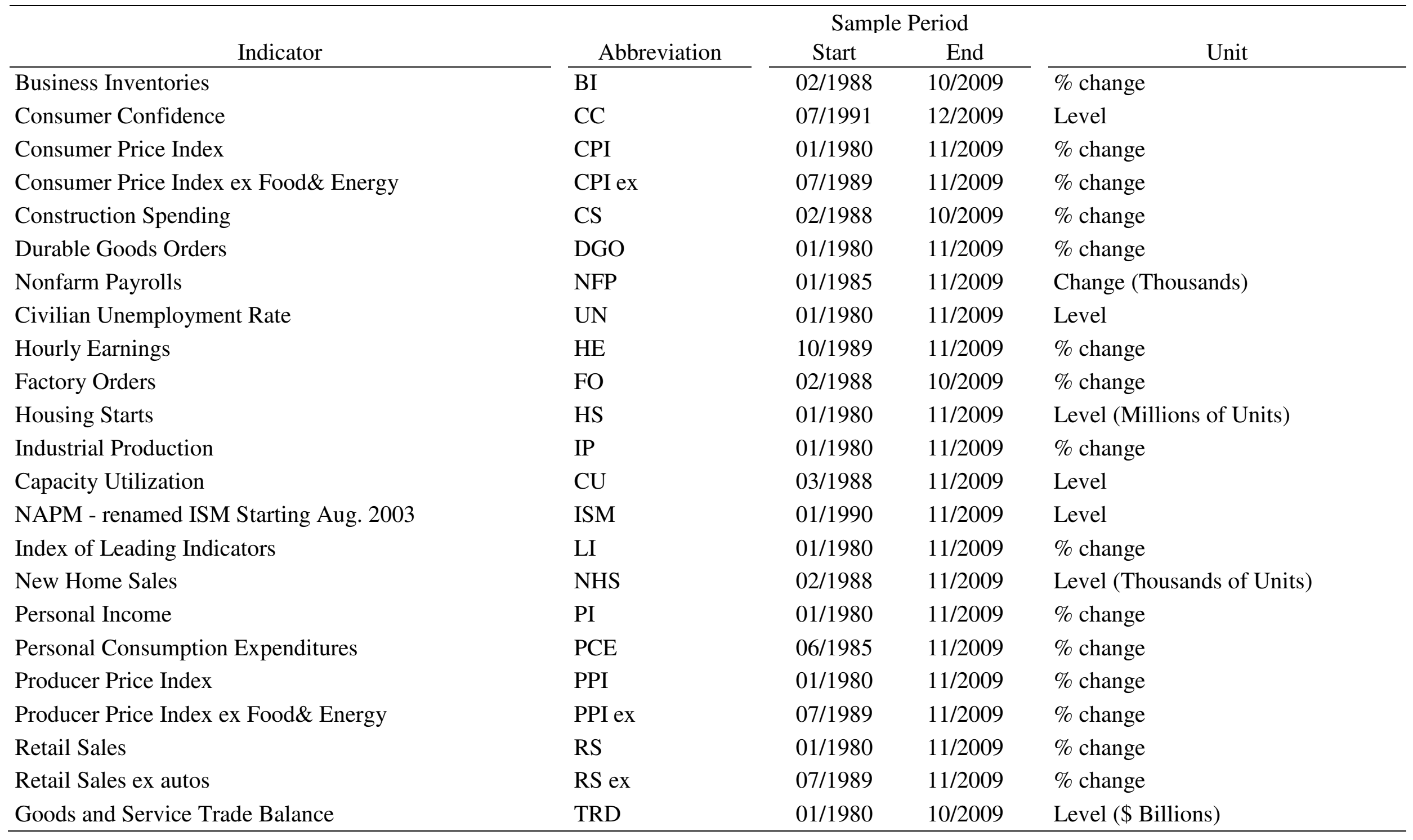


Table 2: Summary Statistics

\begin{tabular}{|c|c|c|c|c|c|c|c|}
\hline \multirow[b]{2}{*}{ Indicator } & \multirow[b]{2}{*}{$\mathrm{N}$} & \multicolumn{2}{|c|}{ Actual } & \multicolumn{2}{|c|}{ Forecast } & \multicolumn{2}{|c|}{ Surprise } \\
\hline & & $\mu$ & $\sigma$ & $\mu$ & $\sigma$ & $\mu$ & $\sigma$ \\
\hline ISM & 239 & 51.579 & 5.622 & 51.630 & 5.418 & -0.051 & 2.022 \\
\hline UN & 359 & 6.150 & 1.514 & 6.188 & 1.518 & -0.019 & 0.164 \\
\hline $\mathrm{HE}$ & 240 & 0.273 & 0.205 & 0.261 & 0.064 & 0.011 & 0.195 \\
\hline PPI & 359 & 0.219 & 0.653 & 0.258 & 0.382 & -0.039 & 0.399 \\
\hline RS ex & 245 & 0.286 & 0.592 & 0.319 & 0.295 & -0.033 & 0.445 \\
\hline CPI & 358 & 0.291 & 0.319 & 0.299 & 0.258 & -0.010 & 0.151 \\
\hline CPI ex & 244 & 0.225 & 0.133 & 0.223 & 0.062 & 0.001 & 0.116 \\
\hline IP & 359 & 0.118 & 0.687 & 0.129 & 0.495 & -0.010 & 0.331 \\
\hline $\mathrm{CU}$ & 261 & 80.203 & 3.586 & 80.190 & 3.579 & 0.006 & 0.370 \\
\hline HS & 359 & 1.473 & 0.349 & 1.461 & 0.338 & 0.012 & 0.098 \\
\hline LI & 359 & 0.150 & 0.764 & 0.141 & 0.602 & 0.009 & 0.321 \\
\hline $\mathrm{CS}$ & 260 & 0.218 & 1.072 & 0.113 & 0.568 & 0.105 & 1.003 \\
\hline FO & 261 & 0.254 & 2.194 & 0.225 & 1.935 & 0.030 & 0.767 \\
\hline BI & 261 & 0.221 & 0.458 & 0.189 & 0.342 & 0.032 & 0.239 \\
\hline TRD & 358 & -21.695 & 19.241 & -21.524 & 19.291 & -0.170 & 2.272 \\
\hline
\end{tabular}

This table reports the means $(\mu)$ and standard deviations $(\sigma)$ of the actual announced value (Actual), the MMS forecast (Forecast) and the resulting surprise calculated as the difference of Actual and Forecast. 
Table 3: Anchoring Bias Test Results

\begin{tabular}{|c|c|c|c|c|c|}
\hline \multirow[b]{2}{*}{ Indicator } & \multicolumn{2}{|c|}{ Static estimates } & \multicolumn{3}{|c|}{ Dynamic estimates } \\
\hline & $\bar{h}$ & $\hat{\gamma}$ & $\begin{array}{c}\bar{h} \\
\text { most frequent }\end{array}$ & $\begin{array}{c}\hat{\gamma} \\
\text { mean }\end{array}$ & $\begin{array}{c}\hat{\gamma} \\
\text { std.dev. }\end{array}$ \\
\hline $\mathrm{CC}$ & 1 & $0.940^{\text {*** }}$ & 1 & 0.922 & 0.365 \\
\hline ISM & 1 & $0.297^{* *}$ & 2 & 0.225 & 0.284 \\
\hline $\mathrm{NF}$ & 2 & 0.070 & 3 & 0.137 & 0.271 \\
\hline UN & 2 & 0.054 & 1 & -0.187 & 0.284 \\
\hline $\mathrm{HE}$ & 2 & $0.516^{* * * *}$ & 2 & 0.439 & 0.264 \\
\hline PPI & 3 & $0.315^{* * *}$ & 3 & 0.303 & 0.146 \\
\hline PPI ex & 1 & $0.205^{* *}$ & 2 & 0.176 & 0.262 \\
\hline $\mathrm{RS}$ & 1 & $0.166^{* * *}$ & 1 & 0.183 & 0.114 \\
\hline RS ex & 1 & $0.275^{* * *}$ & 1 & 0.382 & 0.217 \\
\hline CPI & 3 & $0.150^{* * *}$ & 3 & 0.130 & 0.127 \\
\hline CPI ex & 1 & $-0.214^{* *}$ & 1 & -0.149 & 0.175 \\
\hline IP & 3 & $0.256^{* * *}$ & 2 & 0.204 & 0.173 \\
\hline $\mathrm{CU}$ & 1 & $0.319^{* * *}$ & 1 & 0.268 & 0.122 \\
\hline HS & 1 & $0.281^{* *}$ & 1 & 0.339 & 0.153 \\
\hline DGO & 3 & $0.398^{* * *}$ & 2 & 0.350 & 0.103 \\
\hline NHS & 3 & -0.104 & 1 & 0.557 & 0.228 \\
\hline PI & 2 & 0.094 & 3 & 0.153 & 0.115 \\
\hline PCE & 2 & $0.189^{* * *}$ & 2 & 0.250 & 0.098 \\
\hline LI & 3 & $0.174^{* * *}$ & 3 & 0.150 & 0.107 \\
\hline CS & 3 & $-0.222^{* * *}$ & 1 & -0.247 & 0.087 \\
\hline FO & 3 & $0.040^{* *}$ & 1 & 0.036 & 0.033 \\
\hline BI & 3 & $0.197^{* * *}$ & 2 & 0.260 & 0.108 \\
\hline TRD & 3 & -0.014 & 1 & 0.267 & 0.210 \\
\hline
\end{tabular}

This table reports results of anchoring bias estimates according to

$$
S_{t}=\gamma \cdot\left(F_{t}-A_{h}^{-}\right)+\varepsilon_{t},
$$

where $S_{t}$ denotes surprises, i.e. actual values $\left(A_{t}\right)$ minus MMS forecast $\left(F_{t}\right)$, and $A_{\bar{h}}$ is the $\bar{h}$ month anchor (i.e. the mean of the $\bar{h}$ previously released actuals). The first two columns report the optimal $\bar{h}$ and estimated $\hat{\gamma}$ for a test performed on the full sample. Columns (3) to (5) report the results for rolling window regressions with a fixed length of 10 years. Inference is based on White Standard Errors. ${ }^{*},{ }^{* *},{ }^{* * *}$ indicates significance at the $10 \%, 5 \%$ and $1 \%$ level, respectively. 
Table 4: Impact of Anchoring Adjustments on Forecast Quality

\begin{tabular}{|c|c|c|c|c|c|}
\hline \multirow[b]{2}{*}{ Indicator } & \multirow[b]{2}{*}{$\begin{array}{c}\text { Static } \\
\hat{\gamma}\end{array}$} & \multicolumn{2}{|c|}{ Static adjustment } & \multicolumn{2}{|c|}{ Dynamic adjustment } \\
\hline & & $\Delta$ RMSFE & $\begin{array}{l}\text { Diebold } \\
\text { Mariano }\end{array}$ & $\triangle$ RMSFE & $\begin{array}{l}\text { Diebold } \\
\text { Mariano }\end{array}$ \\
\hline $\mathrm{CC}$ & $0.940^{* * * *}$ & $-8.38 \%$ & $3.0611^{* * * *}$ & $-7.94 \%$ & $2.3913^{* *}$ \\
\hline ISM & $0.297^{* *}$ & $-1.14 \%$ & 1.1600 & $3.36 \%$ & -1.4817 \\
\hline $\mathrm{NF}$ & 0.070 & $-0.15 \%$ & 0.3318 & $3.47 \%$ & $-2.0611^{* *}$ \\
\hline UN & 0.054 & $-0.36 \%$ & 1.0481 & $1.06 \%$ & -1.1930 \\
\hline $\mathrm{HE}$ & $0.516^{* * *}$ & $-6.09 \%$ & $1.9677^{*}$ & $-2.11 \%$ & 0.3788 \\
\hline PPI & $0.315^{* * *}$ & $-6.81 \%$ & $2.2901^{* *}$ & $-4.63 \%$ & 1.5963 \\
\hline PPI ex & $0.205^{* *}$ & $-2.44 \%$ & 1.0270 & $-1.98 \%$ & 0.7873 \\
\hline $\mathrm{RS}$ & $0.166^{* * *}$ & $-5.73 \%$ & $2.2316^{* *}$ & $15.41 \%$ & -0.9479 \\
\hline RS ex & $0.275^{* * *}$ & $-6.39 \%$ & $2.2695^{* *}$ & $-7.87 \%$ & 1.5492 \\
\hline CPI & $0.150^{* * *}$ & $-2.58 \%$ & $1.7648^{*}$ & $-2.21 \%$ & 1.0900 \\
\hline CPI ex & $-0.214^{* *}$ & $-2.42 \%$ & 1.5437 & $-0.12 \%$ & 0.0846 \\
\hline IP & $0.256^{* * *}$ & $-6.01 \%$ & $1.7234^{*}$ & $-4.82 \%$ & 1.0857 \\
\hline $\mathrm{CU}$ & $0.319^{* * *}$ & $-3.65 \%$ & $1.7317^{*}$ & $-3.24 \%$ & 1.3350 \\
\hline HS & $0.281^{* *}$ & $-1.02 \%$ & 0.9885 & $1.22 \%$ & -1.0694 \\
\hline DGO & $0.398^{* * * *}$ & $-4.56 \%$ & $3.2828^{* * * *}$ & $-5.71 \%$ & $2.5341^{* *}$ \\
\hline NHS & -0.104 & $-0.33 \%$ & 0.9153 & $1.36 \%$ & -0.8149 \\
\hline PI & 0.094 & $-0.53 \%$ & 0.9634 & $0.56 \%$ & -0.7182 \\
\hline PCE & $0.189^{* * *}$ & $-6.95 \%$ & $1.8066^{*}$ & $-1.09 \%$ & 0.2461 \\
\hline LI & $0.174^{* * *}$ & $-6.75 \%$ & 1.0762 & $-1.56 \%$ & 0.8598 \\
\hline $\mathrm{CS}$ & $-0.222^{* * *}$ & $-1.90 \%$ & $2.0148^{* *}$ & $-2.21 \%$ & 1.3186 \\
\hline $\mathrm{FO}$ & $0.040^{* *}$ & $-0.70 \%$ & 0.9962 & $0.12 \%$ & -0.0589 \\
\hline BI & $0.197^{* * *}$ & $-1.40 \%$ & 1.2159 & $-1.87 \%$ & 1.2158 \\
\hline TRD & -0.014 & $-0.00 \%$ & 0.1045 & $3.91 \%$ & $-1.9588^{*}$ \\
\hline
\end{tabular}

This table reports adjustments survey forecasts according to the estimated anchoring bias

$$
F_{t}^{a d j}=(1+\hat{\gamma}) \cdot F_{t}-\hat{\gamma} \cdot A_{h}^{-},
$$

where $F_{t}$ denotes MMS forecast $\left(F_{t}\right)$ and $A_{\bar{h}}$ is the $\bar{h}$ months anchor (i.e. the mean of the $\bar{h}$ previously released actuals). For convenience, column (1) redisplays static estimates of $\hat{\gamma}$ . Columns (2)-(5) report the results of a Diebold-Mariano test with small sample adjustment for the equality of mean squared errors (MSE). $\mathrm{H}_{0}$ : MSE of $F_{t}^{\text {adj }}=$ MSE of $F_{t}$. Inference of $\hat{\gamma}$ is based on White standard errors. ${ }^{*},{ }^{* *},{ }^{* * *}$ indicates significance at the $10 \%, 5 \%$ and $1 \%$ level, respectively. 
Table 5: Best Performing Time series Model

\begin{tabular}{lccccc}
\hline Indicator & $\begin{array}{c}\text { Most frequent } \\
\text { ARIMA(p,d,q) } \\
\text { specification }\end{array}$ & $\begin{array}{c}\text { RMSFE } \\
\text { ARIMA }\end{array}$ & $\begin{array}{c}\text { RMSFE } \\
\text { MMS }\end{array}$ & $\Delta$ RMSFE & $\begin{array}{c}\text { Diebold } \\
\text { Mariano } \\
\text { Test }\end{array}$ \\
\hline CC & $1,0,0$ & 6.48 & 5.20 & $-19.7 \%$ & $-5.46^{* * * *}$ \\
ISM & $0,1,0$ & 2.38 & 2.06 & $-13.5 \%$ & $-3.71^{* * * *}$ \\
NF & $1,0,1$ & 136.71 & 109.97 & $-19.6 \%$ & $-4.17^{* * *}$ \\
UN & $2,0,1$ & 0.21 & 0.17 & $-15.3 \%$ & $-2.84^{* * *}$ \\
HE & $3,1,1$ & 0.15 & 0.13 & $-10.8 \%$ & $-1.87^{* *}$ \\
PPI & $1,1,1$ & 0.72 & 0.43 & $-39.6 \%$ & $-2.88^{* * *}$ \\
PPI ex & $0,1,1$ & 2.10 & 0.29 & $-86.2 \%$ & -1.04 \\
RS & $2,1,1$ & 1.15 & 0.73 & $-36.8 \%$ & $-3.14^{* * *}$ \\
RS ex & $0,1,1$ & 0.96 & 0.53 & $-45.0 \%$ & $-2.25^{* *}$ \\
CPI & $1,1,1$ & 0.26 & 0.13 & $-49.3 \%$ & $-3.33^{* * *}$ \\
CPI ex & $0,1,1$ & 0.31 & 0.10 & $-68.3 \%$ & $-1.89^{* *}$ \\
IP & $0,1,1$ & 0.63 & 0.33 & $-47.2 \%$ & $-4.77^{* * *}$ \\
CU & $1,0,0$ & 0.56 & 0.40 & $-28.4 \%$ & $-4.18^{* * *}$ \\
HS & $2,0,0$ & 1.71 & 0.08 & $-95.2 \%$ & -1.54 \\
DGO & $2,1,1$ & 3.12 & 2.81 & $-9.8 \%$ & $-2.50^{* *}$ \\
NHS & $1,0,1$ & 74.11 & 67.98 & $-8.3 \%$ & $-1.87^{* *}$ \\
PI & $0,1,1$ & 0.46 & 0.31 & $-32.7 \%$ & $-3.30^{* * * *}$ \\
PCE & $2,1,1$ & 0.43 & 0.20 & $-52.7 \%$ & $-2.78^{* * * *}$ \\
LI & $0,1,1$ & 0.46 & 0.19 & $-59.3 \%$ & $-4.57^{* * *}$ \\
CS & $0,1,1$ & 1.22 & 0.91 & $-25.4 \%$ & $-1.522^{* * * *}$ \\
FO & $2,1,1$ & 2.29 & 0.74 & $-67.5 \%$ & $-2.97^{* * *}$ \\
BI & $0,1,1$ & 0.37 & 0.25 & $-32.7 \%$ & $-3.75^{* * *}$ \\
TRD & $1,0,1$ & 2.93 & 2.46 & $-16.2 \%$ & $-3.01^{* * *}$ \\
\hline
\end{tabular}

In column (1) this table reports the most frequent ARIMA specification from the rolling estimation procedure. Column (2) and (3) report the root mean squared forecast errors (RMSFE) of the time series forecasts and the original MMS data. Column (4) shows the percentage difference of the RMSFE, where negative values indicate the superiority of the MMS data. In column (5) contains the results of a modified Diebold- Mariano test for MSE equality $\left(\mathrm{H}_{0}: \mathrm{MSE}^{\text {time series forecast }}=\mathrm{MSE}^{\mathrm{MMS}}\right) .{ }^{*},{ }^{* *},{ }^{* * *}$ indicates significance at the $10 \%, 5 \%$ and $1 \%$ level, respectively. 
Table 6: Residual Correlations

\begin{tabular}{lccc}
\hline Indicator & $\operatorname{Var}\left(\widehat{\varepsilon_{t}}\right)$ & $\operatorname{Var}\left(\widehat{Z}_{t}\right)$ & Correlation $\left(\widehat{Z}_{t}, \widehat{\varepsilon}_{t}\right)$ \\
\hline CC & 41.73 & 5.06 & $0.68^{* * * *}$ \\
ISM & 5.31 & 0.92 & $0.50^{* * * *}$ \\
NF & 19000.00 & 5182.06 & $0.60^{* * *}$ \\
UN & 0.04 & 0.01 & $0.52^{* * * *}$ \\
HE & 0.04 & 0.00 & $0.32^{* * * *}$ \\
PPI & 0.40 & 0.12 & $0.82^{* * *}$ \\
PPI ex & 0.08 & 0.01 & $0.36^{* * * *}$ \\
RS & 1.16 & 0.55 & $0.77^{* * * *}$ \\
RS ex & 0.35 & 0.09 & $0.69^{* * * *}$ \\
CPI & 0.07 & 0.04 & $0.81^{* * *}$ \\
CPI ex & 0.01 & 0.00 & $0.24^{* * *}$ \\
IP & 0.39 & 0.17 & $0.86^{* * * *}$ \\
CU & 0.28 & 0.08 & $0.74^{* * *}$ \\
HS & 0.01 & 0.00 & $0.57^{* * * *}$ \\
DGO & 10.79 & 1.40 & $0.50^{* * *}$ \\
NHS & 4396.60 & 447.31 & $0.41^{* * * *}$ \\
PI & 0.18 & 0.08 & $0.71^{* * *}$ \\
PCE & 0.22 & 0.14 & $0.89^{* * * *}$ \\
LI & 0.50 & 0.29 & $0.90^{* * * *}$ \\
CS & 1.10 & 0.32 & $0.37^{* * *}$ \\
FO & 4.16 & 3.15 & $0.93^{* * * *}$ \\
BI & 0.12 & 0.04 & $0.77^{* * *}$ \\
TRD & 6.69 & 1.30 & $0.53^{* * * *}$ \\
\hline
\end{tabular}

This table reports the variances of the innovation in announcements $\hat{\varepsilon}_{t}$ and the approximated additional information component in survey forecasts $\hat{Z}_{t}$ which we retrieved from optimally fitted distributed lag models as described in section 1. In addition the correlation of $\hat{\varepsilon}_{t}$ and $\hat{Z}_{t}$ is provided. ${ }^{* * * *}$,"* , and "denotes significance of these correlations at the $1 \%, 5 \%$, and $10 \%$ level respectively. 
Table 7: Additional Information Content for Selected Indicators

\begin{tabular}{|c|c|c|c|c|c|c|}
\hline Indicator & $\mathrm{CC}$ & DGO & IP & NFP & PPI ex & $\mathrm{RS}$ ex \\
\hline$\overline{\mathrm{HS}}$ & & & $-0.004 * *$ & $0.762 * * *$ & & $0.001 *$ \\
\hline PPI & & $0.064 * * *$ & $0.013 * *$ & $2.668 * * *$ & & $0.013 * * *$ \\
\hline UN & & $0.001 * *$ & $0.001 * * *$ & & & $0.000 * * *$ \\
\hline PCE & $0.749 * * *$ & $0.213 * * *$ & $-0.098 * *$ & $26.725 * * *$ & $0.042 * * *$ & \\
\hline $\mathrm{CU}$ & & & $0.373 * * *$ & & & \\
\hline $\mathrm{HE}$ & $-0.309^{*}$ & $0.186^{*}$ & $-0.108 * * *$ & & & \\
\hline NHS & & & & & & $-0.122 * *$ \\
\hline RS & & $0.108 * *$ & & $7.890 *$ & & \\
\hline \multicolumn{7}{|l|}{ TRD } \\
\hline LI & & & $0.306 * * *$ & & $0.023 *$ & $0.197 * *$ \\
\hline BI & & $0.786^{*}$ & & $82.475 * * *$ & $0.195 * * *$ & \\
\hline $\mathrm{CC}$ & & $0.647 * * *$ & & & & \\
\hline ISM & & & $-0.051 * * *$ & & $0.017 * * *$ & \\
\hline CS & $1.124 *$ & & & & & \\
\hline CPI ex & & & & & & $-0.035^{* *}$ \\
\hline IP & & & $-0.000^{*}$ & $0.059 * * *$ & & \\
\hline PI & & & & & $0.017 * *$ & \\
\hline PPI ex & & & & $31.745^{* *}$ & & \\
\hline \multicolumn{7}{|l|}{ CPI } \\
\hline FO & & $0.109 * *$ & $0.040 * *$ & $10.280 * *$ & $0.010 * *$ & \\
\hline NFP & & $-0.162 * * *$ & & & & $0.073 * * *$ \\
\hline DGO & & & & & & $-0.067 * *$ \\
\hline RS ex & & & & & $-0.001 * * *$ & \\
\hline
\end{tabular}

This table report the regression results of the additional information on available macroeconomic information seven days prior to the next announcement:

$Z_{t}=\alpha+\beta M_{t}+\varphi_{t}$

where $Z_{t}$ denotes the approximated additional information component in survey forecasts and $M_{t}$ a vector containing the available macroeconomic information set for the 23 considered indicators seven days prior to an announcement. A stepwise regression approach was used to obtain the models. *, **, *** indicates significance at the $10 \%, 5 \%$ and $1 \%$ level, respectively. 
Table 8: Additional Information Content R-squared and Indicator Frequency

\begin{tabular}{lccc} 
Indicator & \# of variables in $\mathrm{M}_{\mathrm{t}}$ & $\mathrm{R}^{2}$ & Frequency of indicator in $\mathrm{M}_{\mathrm{t}}$ \\
\hline CC & 3 & 0.121 & 10 \\
ISM & 10 & 0.213 & 14 \\
NF & 8 & 0.312 & 11 \\
UN & 6 & 0.132 & 14 \\
HE & 6 & 0.391 & 5 \\
PPI & 3 & 0.084 & 9 \\
PPI ex & 7 & 0.395 & 6 \\
RS & 6 & 0.241 & 8 \\
RS ex & 8 & 0.439 & 3 \\
CPI & 2 & 0.070 & 6 \\
CPI ex & 6 & 0.239 & 4 \\
IP & 10 & 0.399 & 7 \\
CU & 10 & 0.302 & 4 \\
HS & 9 & 0.390 & 5 \\
DGO & 9 & 0.525 & 3 \\
NHS & 7 & 0.319 & 6 \\
PI & 8 & 0.429 & 3 \\
PCE & 7 & 0.808 & 7 \\
LI & 7 & 0.190 & 6 \\
CS & 6 & 0.572 & 6 \\
FO & 8 & 0.768 & 6 \\
BI & 11 & 0.381 & \\
TRD & 9 & 0.513 & \\
Min & & 0.070 & \\
Max & 0.808 & \\
Mean & & 0.358 & \\
Median & & 0.381 & \\
\hline
\end{tabular}

This table reports the number of explanatory variables in the vector of available macroeconomic information $M_{t}$ in the regression $Z_{t}=\alpha+\beta M_{t}+\varphi_{t}$, the associated Rsquared and the frequency of each indicator in $M_{t}$, i.e. in how many cases the respective indicator contributes to the explanation of $Z_{t}$. 
Table 9: Gamma Decomposition

\begin{tabular}{|c|c|c|c|c|c|}
\hline \multirow[b]{3}{*}{ Indicator } & \multicolumn{2}{|c|}{ Test results } & \multicolumn{3}{|c|}{ Model based approximation } \\
\hline & $\begin{array}{l}\text { Static } \\
\text { estimates }\end{array}$ & $\begin{array}{l}\text { Dynamic } \\
\text { estimates }\end{array}$ & total & $\begin{array}{l}\text { inefficiency } \\
\text { component }\end{array}$ & $\begin{array}{l}\text { add. information } \\
\text { component }\end{array}$ \\
\hline & $\hat{\gamma}$ & mean $\hat{\gamma}$ & $\hat{\gamma}$ & $\hat{\gamma}_{1}$ & $\hat{\gamma}_{2}$ \\
\hline $\mathrm{CC}$ & $0.940^{* * * *}$ & 0.922 & 0.940 & -0.000 & 0.940 \\
\hline ISM & $0.297^{* *}$ & 0.225 & 0.297 & 0.118 & 0.179 \\
\hline NF & 0.070 & 0.137 & 0.070 & -0.028 & 0.098 \\
\hline UN & 0.054 & -0.187 & 0.049 & 0.031 & 0.018 \\
\hline $\mathrm{HE}$ & $0.516^{* * *}$ & 0.439 & 0.516 & 0.486 & 0.030 \\
\hline PPI & $0.315^{* * *}$ & 0.303 & 0.311 & -0.003 & 0.314 \\
\hline PPI ex & $0.205^{* *}$ & 0.176 & 0.205 & 0.201 & 0.005 \\
\hline $\mathrm{RS}$ & $0.166^{* * *}$ & 0.183 & 0.166 & 0.136 & 0.030 \\
\hline RS ex & $0.275^{* * *}$ & 0.382 & 0.275 & 0.033 & 0.242 \\
\hline CPI & $0.150^{* * *}$ & 0.130 & 0.149 & 0.060 & 0.090 \\
\hline CPI ex & $-0.214^{* *}$ & -0.149 & -0.214 & -0.158 & -0.056 \\
\hline IP & $0.256^{* * *}$ & 0.204 & 0.254 & -0.244 & 0.498 \\
\hline $\mathrm{CU}$ & $0.319^{* * *}$ & 0.268 & 0.320 & 0.035 & 0.285 \\
\hline $\mathrm{HS}$ & $0.281^{* *}$ & 0.339 & 0.280 & 0.072 & 0.208 \\
\hline DGO & $0.398^{* * *}$ & 0.350 & 0.399 & 0.225 & 0.174 \\
\hline NHS & -0.104 & 0.557 & -0.102 & -0.211 & 0.108 \\
\hline PI & 0.094 & 0.153 & 0.095 & 0.053 & 0.041 \\
\hline PCE & $0.189^{* * *}$ & 0.250 & 0.189 & 0.127 & 0.062 \\
\hline LI & $0.174^{* * *}$ & 0.150 & 0.178 & 0.026 & 0.152 \\
\hline $\mathrm{CS}$ & $-0.222^{* * *}$ & -0.247 & -0.217 & -0.139 & -0.078 \\
\hline FI & $0.040^{* *}$ & 0.036 & 0.040 & -0.002 & 0.042 \\
\hline BI & $0.197^{* * *}$ & 0.260 & 0.197 & -0.036 & 0.233 \\
\hline TRD & -0.014 & 0.267 & -0.016 & -0.122 & 0.106 \\
\hline
\end{tabular}

This table reports results of anchoring bias estimations:

$$
S_{t}=\gamma \cdot\left(F_{t}-A_{h}^{-}\right)+\varepsilon_{t},
$$

where $S_{t}$ denotes surprises, i.e. actual values $\left(A_{t}\right)$ minus MMS forecast $\left(F_{t}\right)$, and $A_{\bar{h}}$ is the $\bar{h}$ months anchor (i.e. the mean of the $\bar{h}$ previously released actuals). Column (1) contains the coefficients from the static test setting; column (2) reports the mean coefficients from the rolling estimation. Column (3) to (5) show the corresponding approximations of $\hat{\gamma}$ and its decomposition into an "inefficiency" $\left(\hat{\gamma}_{1}\right)$ and an "additional information" $\left(\hat{\gamma}_{2}\right)$ component:

$$
\begin{aligned}
& \hat{\gamma}_{1}=\frac{\operatorname{Cov}\left(y_{t-1}^{\prime}, x_{t-1}^{\prime}\right)+\operatorname{Cov}\left(e_{t}, x_{t-1}^{\prime}\right)}{\operatorname{Var}\left(x_{t-1}^{\prime}\right)+\operatorname{Var}\left(Z_{t}\right)+2 \cdot \operatorname{Cov}\left(Z_{t}, x_{t-1}^{\prime}\right)} \\
& \hat{\gamma}_{2}=\frac{\operatorname{Cov}\left(e_{t}, Z_{t}\right)-\operatorname{Var}\left(Z_{t}\right)-\operatorname{Cov}\left(Z_{t}, x_{t-1}^{\prime}\right)}{\operatorname{Var}\left(x_{t-1}^{\prime}\right)+\operatorname{Var}\left(Z_{t}\right)+2 \cdot \operatorname{Cov}\left(Z_{t}, x_{t-1}^{\prime}\right)}
\end{aligned}
$$


CFR working paper series

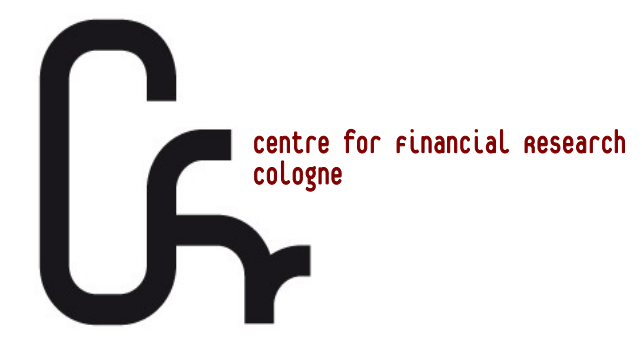

CfR working papers are available for download from www.cfr-cologne.de.

Hardcopies can be ordered from: centre for financial Research (CFR), albertus magnus platz, 50923 koeln, Germany.

2011

No. Author(s) Title

11-13 D. Hess, S. Orbe Irrationality or Efficiency of Macroeconomic Survey Forecasts? Implications from the Anchoring Bias Test

11-12 D. Hess, P. Immenkötter Optimal Leverage, its Benefits, and the Business Cycle

11-11 N. Heinrichs, D. Hess, Extended Dividend, Cash Flow and Residual Income Valuation C. Homburg, M. Lorenz, Models - Accounting for Deviations from Ideal Conditions

S. Sievers

11-10 A. Kempf, O. Korn,

S. Saßning

Portfolio Optimization using Forward - Looking Information

11-09 V. Agarwal, S. Ray

Determinants and Implications of Fee Changes in the Hedge Fund Industry

11-08 G. Cici, L.-F. Palacios

On the Use of Options by Mutual Funds: Do They Know What They Are Doing?

11-07 V. Agarwal, G. D. Gay, Window Dressing in Mutual Funds

L. Ling

11-06 N. Hautsch, D. Hess, The Impact of Macroeconomic News on Quote Adjustments,

D. Veredas

Noise, and Informational Volatility

11-05 G. Cici

The Prevalence of the Disposition Effect in Mutual Funds' Trades

11-04 S. Jank

Mutual Fund Flows, Expected Returns and the Real Economy

11-03 G.Fellner, E.Theissen

Short Sale Constraints, Divergence of Opinion and Asset Value: Evidence from the Laboratory

11-02 S.Jank

Are There Disadvantaged Clienteles in Mutual Funds?

11-01 V. Agarwal, C. Meneghetti The Role of Hedge Funds as Primary Lenders

2010

No. Author(s) Title

10-20 G. Cici, S. Gibson,

Missing the Marks? Dispersion in Corporate Bond Valuations J.J. Merrick Jr. Across Mutual Funds

$10-19$

J. Hengelbrock,

Market Response to Investor Sentiment 


\section{E. Theissen, C. Westheide}

10-18

G. Cici, S. Gibson

10-17 D. Hess, D. Kreutzmann,

O. Pucker

10-16 S. Jank, M. Wedow

10-15 G. Cici, A. Kempf, A. Puetz

10-14 J. Grammig, S. Jank

10-13 S. Jank, M. Wedow

10-12 S. Artmann, P. Finter,

A. Kempf, S. Koch,

E. Theissen

10-11 M. Chesney, A. Kempf

10-10 S. Frey, P. Herbst

10-09 V. Agarwal, W. Jiang,

Y. Tang, B. Yang

10-08 V. Agarwal, V. Fos, W. Jiang

10-07 V. Agarwal, G. Bakshi, J. Huij

10-06 J. Grammig, F. J. Peter

10-05 K. Drachter, A. Kempf

10-04 J. Fang, A. Kempf, M. Trapp

10-03 P. Finter, A. NiessenRuenzi, S. Ruenzi

10-02 D. Hunter, E. Kandel,

S. Kandel, R. Wermers

10-01 S. Artmann, P. Finter,

A. Kempf
The Performance of Corporate-Bond Mutual Funds:

Evidence Based on Security-Level Holdings

Projected Earnings Accuracy and the Profitability of Stock Recommendations

Sturm und Drang in Money Market Funds: When Money Market Funds Cease to Be Narrow

Caught in the Act:

How Hedge Funds Manipulate their Equity Positions

Creative Destruction and Asset Prices

Purchase and Redemption Decisions of Mutual Fund Investors and the Role of Fund Families

The Cross-Section of German Stock Returns:

New Data and New Evidence

The Value of Tradeability

The Influence of Buy-side Analysts on

Mutual Fund Trading

Uncovering Hedge Fund Skill from the Portfolio Holdings They Hide

Inferring Reporting Biases in Hedge Fund Databases from Hedge Fund Equity Holdings

Do Higher-Moment Equity Risks Explain Hedge Fund Returns?

Tell-Tale Tails

Höhe, Struktur und Determinanten der ManagervergütungEine Analyse der Fondsbranche in Deutschland

Fund Manager Allocation

The Impact of Investor Sentiment on the German Stock Market

Endogenous Benchmarks

Determinants of Expected Stock Returns: Large Sample Evidence from the German Market
No. Author(s)

09-17

E. Theissen

09-16

M. Trapp

09-14

A. Kempf, O. Korn,

M. Uhrig-Homburg

$09-13$
Title

Price Discovery in Spot and Futures Markets:

A Reconsideration

Trading the Bond-CDS Basis - The Role of Credit Risk and Liquidity

The Term Structure of Illiquidity Premia

Time-Varying Credit Risk and Liquidity Premia in Bond and CDS Markets 
Explaining the Bond-CDS Basis - The Role of Credit Risk and Liquidity

09-11 S. J. Taylor, P. K. Yadav, Y. Zhang

09-10 A. Kempf, C. Merkle,

A. Niessen

09-09 V. Fotak, V. Raman,

P. K. Yadav

09-08 F. Bardong, S.M. Bartram, P.K. Yadav

09-07 S. J. Taylor, P. K. Yadav, Y. Zhang

09-06 S. Frey, P. Sandas

09-05 H. Beltran-Lopez, P. Giot, J. Grammig

09-04 J. Fang, S. Ruenzi

09-03 A. Banegas, B. Gillen,

A. Timmermann,

R. Wermers

09-02 J. Grammig, A. Schrimpf, M. Schuppli

09-01 O. Korn, P. Koziol
Cross-sectional analysis of risk-neutral skewness

Low Risk and High Return - How Emotions Shape Expectations on the Stock Market

Naked Short Selling: The Emperor`s New Clothes?

Informed Trading, Information Asymmetry and Pricing of Information Risk: Empirical Evidence from the NYSE

The information content of implied volatilities and model-free volatility expectations: Evidence from options written on individual stocks

The Impact of Iceberg Orders in Limit Order Books

Commonalities in the Order Book

Rapid Trading bei deutschen Aktienfonds:

Evidenz aus einer großen deutschen Fondsgesellschaft

The Performance of European Equity Mutual Funds

Long-Horizon Consumption Risk and the Cross-Section of Returns: New Tests and International Evidence

The Term Structure of Currency Hedge Ratios

2008

\begin{tabular}{|c|c|c|}
\hline No. & Author(s) & Title \\
\hline $08-12$ & $\begin{array}{l}\text { U. Bonenkamp, } \\
\text { C. Homburg, A. Kempf }\end{array}$ & Fundamental Information in Technical Trading Strategies \\
\hline 08-11 & O. Korn & Risk Management with Default-risky Forwards \\
\hline 08-10 & J. Grammig, F.J. Peter & $\begin{array}{l}\text { International Price Discovery in the Presence } \\
\text { of Market Microstructure Effects }\end{array}$ \\
\hline 08-09 & C. M. Kuhnen, A. Niessen & Public Opinion and Executive Compensation \\
\hline $08-08$ & A. Pütz, S. Ruenzi & $\begin{array}{l}\text { Overconfidence among Professional Investors: Evidence from } \\
\text { Mutual Fund Managers }\end{array}$ \\
\hline 08-07 & P. Osthoff & What matters to SRI investors? \\
\hline 08-06 & A. Betzer, E. Theissen & $\begin{array}{l}\text { Sooner Or Later: Delays in Trade Reporting by Corporate } \\
\text { Insiders }\end{array}$ \\
\hline 08-05 & P. Linge, E. Theissen & $\begin{array}{l}\text { Determinanten der Aktionärspräsenz auf } \\
\text { Hauptversammlungen deutscher Aktiengesellschaften }\end{array}$ \\
\hline 08-04 & $\begin{array}{l}\text { N. Hautsch, D. Hess, } \\
\text { C. Müller }\end{array}$ & Price Adjustment to News with Uncertain Precision \\
\hline $08-03$ & $\begin{array}{l}\text { D. Hess, H. Huang, } \\
\text { A. Niessen }\end{array}$ & $\begin{array}{l}\text { How Do Commodity Futures Respond to Macroeconomic } \\
\text { News? }\end{array}$ \\
\hline 08-02 & R. Chakrabarti, & Corporate Governance in India \\
\hline
\end{tabular}




\begin{tabular}{|c|c|c|}
\hline No. & Author(s) & Title \\
\hline $07-16$ & $\begin{array}{l}\text { M. Bär, A. Niessen, } \\
\text { S. Ruenzi }\end{array}$ & $\begin{array}{l}\text { The Impact of Work Group Diversity on Performance: } \\
\text { Large Sample Evidence from the Mutual Fund Industry }\end{array}$ \\
\hline $07-15$ & A. Niessen, S. Ruenzi & $\begin{array}{l}\text { Political Connectedness and Firm Performance: } \\
\text { Evidence From Germany }\end{array}$ \\
\hline $07-14$ & O. Korn & Hedging Price Risk when Payment Dates are Uncertain \\
\hline $07-13$ & A. Kempf, P. Osthoff & SRI Funds: Nomen est Omen \\
\hline $07-12$ & $\begin{array}{l}\text { J. Grammig, E. Theissen, } \\
\text { O. Wuensche }\end{array}$ & Time and Price Impact of a Trade: A Structural Approach \\
\hline 07-11 & V. Agarwal, J. R. Kale & $\begin{array}{l}\text { On the Relative Performance of Multi-Strategy and Funds of } \\
\text { Hedge Funds }\end{array}$ \\
\hline $07-10$ & $\begin{array}{l}\text { M. Kasch-Haroutounian, } \\
\text { E. Theissen }\end{array}$ & Competition Between Exchanges: Euronext versus Xetra \\
\hline 07-09 & $\begin{array}{l}\text { V. Agarwal, N. D. Daniel, } \\
\text { N. Y. Naik }\end{array}$ & Do hedge funds manage their reported returns? \\
\hline $07-08$ & $\begin{array}{l}\text { N. C. Brown, K. D. Wei, } \\
\text { R. Wermers }\end{array}$ & $\begin{array}{l}\text { Analyst Recommendations, Mutual Fund Herding, and } \\
\text { Overreaction in Stock Prices }\end{array}$ \\
\hline $07-07$ & A. Betzer, E. Theissen & $\begin{array}{l}\text { Insider Trading and Corporate Governance: } \\
\text { The Case of Germany }\end{array}$ \\
\hline 07-06 & V. Agarwal, L. Wang & Transaction Costs and Value Premium \\
\hline $07-05$ & J. Grammig, A. Schrimpf & $\begin{array}{l}\text { Asset Pricing with a Reference Level of Consumption: } \\
\text { New Evidence from the Cross-Section of Stock Returns }\end{array}$ \\
\hline 07-04 & $\begin{array}{l}\text { V. Agarwal, N.M. Boyson, } \\
\text { N.Y. Naik }\end{array}$ & $\begin{array}{l}\text { Hedge Funds for retail investors? } \\
\text { An examination of hedged mutual funds }\end{array}$ \\
\hline $07-03$ & D. Hess, A. Niessen & $\begin{array}{l}\text { The Early News Catches the Attention: } \\
\text { On the Relative Price Impact of Similar Economic Indicators }\end{array}$ \\
\hline $07-02$ & $\begin{array}{l}\text { A. Kempf, S. Ruenzi, } \\
\text { T. Thiele }\end{array}$ & $\begin{array}{l}\text { Employment Risk, Compensation Incentives and Managerial } \\
\text { Risk Taking - Evidence from the Mutual Fund Industry - }\end{array}$ \\
\hline $07-01$ & M. Hagemeister, A. Kempf & $\begin{array}{l}\text { CAPM und erwartete Renditen: Eine Untersuchung auf Basis } \\
\text { der Erwartung von Marktteilnehmern }\end{array}$ \\
\hline
\end{tabular}

No. Author(s) Title

06-13 S. Čeljo-Hörhager, A. Niessen

06-12 R. Wermers, Y. Wu, J. Zechner

06-11 U. v. Lilienfeld-Toal, S. Ruenzi

06-10 A. Kempf, P. Osthoff
How do Self-fulfilling Prophecies affect Financial Ratings? - An experimental study

Portfolio Performance, Discount Dynamics, and the Turnover of Closed-End Fund Managers

Why Managers Hold Shares of Their Firm: An Empirical Analysis

The Effect of Socially Responsible Investing on Portfolio 


\section{Performance}

06-09 R. Wermers, T. Yao, J. Zhao

06-08 M. Hoffmann, B. Kempa

06-07 K. Drachter, A. Kempf, M. Wagner

06-06 J.P. Krahnen, F.A. Schmid, E. Theissen

06-05 S. Ber, S. Ruenzi

06-04 A. Kempf, D. Mayston

06-03 O. Korn, C. Koziol

06-02 O. Scaillet, L. Barras, R. Wermers

06-01 A. Niessen, S. Ruenzi
The Investment Value of Mutual Fund Portfolio Disclosure

The Poole Analysis in the New Open Economy

Macroeconomic Framework

Decision Processes in German Mutual Fund Companies:

Evidence from a Telephone Survey

Investment Performance and Market Share: A Study of the German Mutual Fund Industry

On the Usability of Synthetic Measures of Mutual Fund NetFlows

Liquidity Commonality Beyond Best Prices

Bond Portfolio Optimization: A Risk-Return Approach

False Discoveries in Mutual Fund Performance: Measuring Luck in Estimated Alphas

Sex Matters: Gender Differences in a Professional Setting

2005

No.

Author(s)

E. Theissen

05-15 T. Foucault, S. Moinas,

E. Theissen

05-14 R. Kosowski,

A. Timmermann,

R. Wermers, H. White

05-13

D. Avramov, R. Wermers

05-12

K. Griese, A. Kempf

05-11

S. Ber, A. Kempf,

S. Ruenzi

05-10 M. Bär, A. Kempf,

S. Ruenzi

05-09 M. Hoffmann

05-08 S. Ruenzi

05-07

05-06

05-05

05-04 M. Hoffmann

05-03 M. Hoffmann
H. Beltran, J. Grammig, A.J. Menkveld

A. Kempf, S. Ruenzi

J. Grammig, E. Theissen

A. Kempf, C. Memmel
Title

An Analysis of Private Investors' Stock Market Return Forecasts

Does Anonymity Matter in Electronic Limit Order Markets

Can Mutual Fund „Stars" Really Pick Stocks?

New Evidence from a Bootstrap Analysis

Investing in Mutual Funds when Returns are Predictable

Liquiditätsdynamik am deutschen Aktienmarkt

Determinanten der Mittelzuflüsse bei deutschen Aktienfonds

Is a Team Different From the Sum of Its Parts?

Evidence from Mutual Fund Managers

Saving, Investment and the Net Foreign Asset Position

Mutual Fund Growth in Standard and Specialist Market Segments

Status Quo Bias and the Number of Alternatives - An Empirical Illustration from the Mutual Fund Industry

Is Best Really Better? Internalization of Orders in an Open Limit Order Book

Understanding the Limit Order Book: Conditioning on Trade Informativeness

Compensating Wages under different Exchange rate Regimes

Fixed versus Flexible Exchange Rates: Evidence from Developing Countries

On the Estimation of the Global Minimum Variance Portfolio 
05-01 S. Frey, J. Grammig Liquidity supply and adverse selection in a pure limit order book market

2004

No. Author(s) Title

04-10

N. Hautsch, D. Hess

Bayesian Learning in Financial Markets - Testing for the Relevance of Information Precision in Price Discovery

04-09 A. Kempf, K. Kreuzberg

Portfolio Disclosure, Portfolio Selection and Mutual Fund Performance Evaluation

04-08 N.F. Carline, S.C. Linn, Operating performance changes associated with corporate P.K. Yadav mergers and the role of corporate governance

04-07 J.J. Merrick, Jr., N.Y. Naik, Strategic Trading Behaviour and Price Distortion in a P.K. Yadav Manipulated Market: Anatomy of a Squeeze

04-06 N.Y. Naik, P.K. Yadav Trading Costs of Public Investors with Obligatory and Voluntary Market-Making: Evidence from Market Reforms

04-05 A. Kempf, S. Ruenzi Family Matters: Rankings Within Fund Families and Fund Inflows

04-04 V. Agarwal, N.D. Daniel, Role of Managerial Incentives and Discretion in Hedge Fund N.Y. Naik Performance

04-03 V. Agarwal, W.H. Fung, $\quad$ Risk and Return in Convertible Arbitrage: J.C. Loon, N.Y. Naik Evidence from the Convertible Bond Market

04-02 A. Kempf, S. Ruenzi Tournaments in Mutual Fund Families

04-01 I. Chowdhury, M. Inflation Dynamics and the Cost Channel of Monetary Hoffmann, A. Schabert Transmission 
